\title{
Testing for a link between personality and mate-choice copying tendency in the Trinidadian guppy (Poecilia reticulata)
}

\author{
by \\ Alisa M. Miller \\ A thesis submitted to the Faculty of Graduate and Postdoctoral Affairs in partial
} fulfillment of the requirements for the degree of

Master of Science

in

Biology

Carleton University

Ottawa, Ontario

(C) 2013

Alisa M. Miller 


\begin{abstract}
An unexplored area of research is whether personality influences how individuals use social information in a mating context. Here, I experimentally tested, using virgin female Trinidadian guppies (Poecilia reticulata), whether (i) exploratory behaviour and boldness in individual females are repeatable over time, (ii) the exploratory tendency of individuals is correlated with their boldness, (iii) mate-choice copying behaviour is repeatable, and (iv) personality is correlated with an individual's tendency to mate-choice copy when given the opportunity to do so. Although both personality scores varied widely among females, neither exploratory or boldness behaviour was significantly repeatable, nor were they correlated with each other. Mate-choice copying behaviour was also not found to be repeatable, and neither personality trait was correlated with an individual's tendency to mate-choice copy. These results suggest that female guppies were able to adjust their exploratory behaviour and boldness independently of one another.
\end{abstract}




\section{ACKNOWLEDGEMENTS}

I thank my supervisor, Dr. Jean-Guy Godin, for his support and guidance throughout my Master's studies, and for giving me the opportunities to conduct research in Trinidad, as well as to present my research at an international conference in Boulder, Colorado. I also thank the other members of my thesis advisory committee, Dr. Sue Bertram and Dr. Howard Rundle, for their advice. Additionally, I would like to thank Dr. Julie Morand-Ferron for stepping in to sit on my committee for my thesis defense as a replacement for Dr. Rundle whilst he was on sabbatical.

I thank the members of the Godin lab - Heather Auld, Dr. Stacey Lee-Jenkins, Anni Auge, Amin Nemati, and Ryan Pusiak - for all of their support and help with everything from tips on creating committee meeting presentations to fish care.

Lastly, I thank my friends and family for their encouragement and motivation over the last two years. I could not have done this with without their ongoing support. 


\section{TABLE OF CONTENTS}

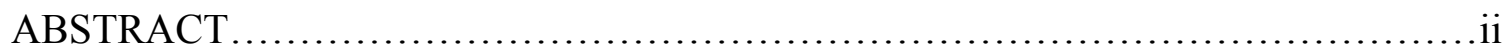

ACKNOWLEDGEMENTS..........................................................

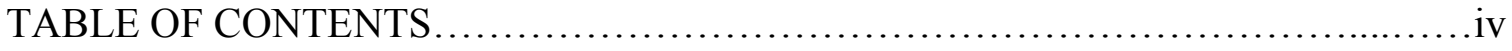

LIST OF TABLES.......................................................................

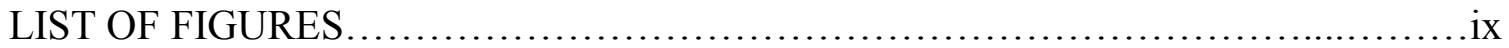

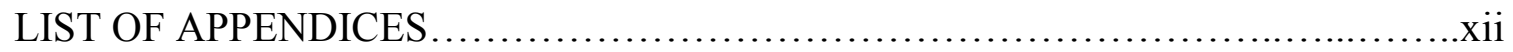

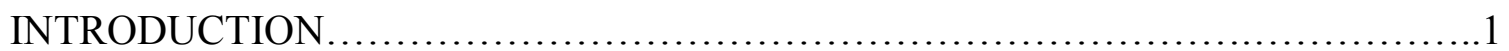

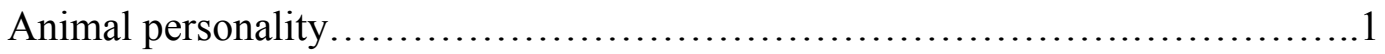

Social information and social learning....................................

Linking personality and social learning tendency - behavioural syndromes.......6

Thesis objective and predictions under test.................................

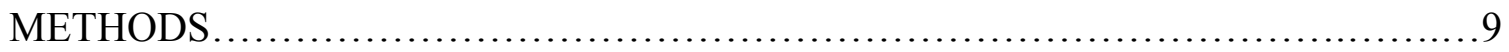

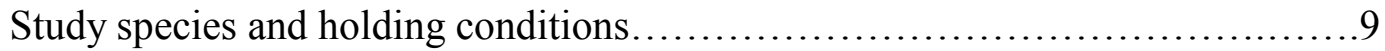

Experimental protocols................................................... 10

Part A: Quantifying personality traits and their repeatability ....................10

i) Repeatability of personality traits.................................11

Personality trait 1: Exploratory behaviour in a novel environment..............................................11

Statistical analyses........................................12 
Personality trait 2: Boldness under predation threat.

Statistical analyses..........................................19

ii) Correlation between exploratory and boldness behaviours.............21

Part B: Social information use and mate-choice copying behaviour..............21

i) Mate-choice copying tendency...................................21

Assessing mating preferences...............................21

Assessing mate-choice copying.................................23

Control for mate-choice copying..............................27

Statistical analyses.............................................

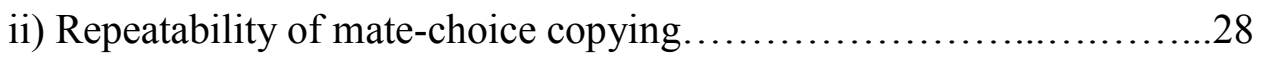

Statistical analyses........................................28

Part C: Linking personality traits and mate-choice copying tendency............29

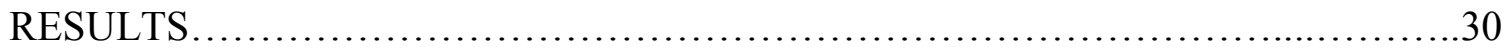

Part A: Personality traits and their repeatability ..............................30

i) Repeatability of exploratory and boldness behaviours..................30

Personality trait 1: Exploratory behaviour in a novel environment................................................... 30

Personality trait 2: Boldness under predation threat...............33

ii) Correlation between exploratory and boldness behaviours..............33

Part B: Social information use and mate-choice copying behaviour..............37

i) Mate-choice copying tendency.....................................

ii) Repeatability of mate-choice copying .................................

Part C: Linking personality traits and mate-choice copying tendency............42

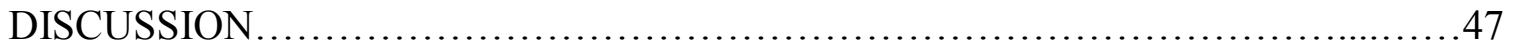


REFERENCES.

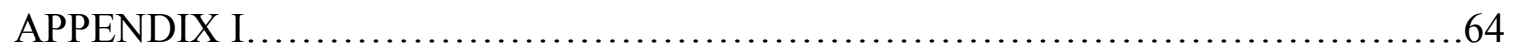

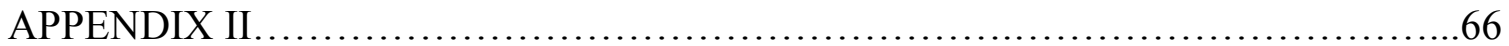




\section{LIST OF TABLES}

Table 1. Correlation matrix using Pearson correlations (r) for measures of exploratory behaviour for week 1 and week 2 . All variables were normalized by $\log _{10}$ transformation prior to analysis. The correlations shown in boldface are statistically significant

$(\mathrm{p}<0.0001)$

Table 2. Correlation matrix using Pearson correlations (r) for measures of boldness for week 1 and week 2 . All variables were normalized by $\log _{10}$ transformation prior to analysis. The correlations shown in boldface are statistically significant $(* \mathrm{p}<0.005$,

$* * \mathrm{p}<0.0001)$

Table 3. Standard body length ( $\mathrm{mm}$ ) for individual focal and model females used in trials in week 1 and week 2. Mean and standard error (SE) measures are shown

below

Table 4. Standard body length $(\mathrm{mm})$ and body coloration pattern (percent black and orange pigmentation on body) of paired stimulus males used in trials in week 1 and week 2. Mean and standard error (SE) measures are shown below 40

Table 5. Correlation matrix using Pearson correlations (r) for measures of exploratory behaviour and boldness for week 1 for females with successful mate-choice copying trials. All variables were normalized by $\log _{10}$ transformation prior to analysis. The correlations shown in boldface are statistically significant $(* p<0.05, * * p<0.005$, $* * * \mathrm{p}<0.0001)$ .43 
Table 6. Correlation matrix using Pearson correlations (r) comparing PC1 scores for exploratory behaviour and boldness with difference scores as a measure of mate-choice tendency for focal females during week $1(n=25)$. No significant results are reported..... .44

Table 7. Correlation matrix using Pearson correlations (r) for measures of exploratory behaviour and boldness for week 2 for females with successful mate-choice copying trials. All variables were normalized by $\log _{10}$ transformation prior to analysis. The correlations shown in boldface are statistically significant $\left({ }^{*} \mathrm{p}<0.01,{ }^{*} \mathrm{p}<0.001\right.$,

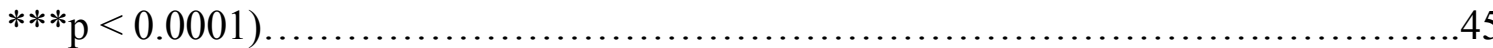

Table 8. Correlation matrix using Pearson correlations (r) comparing PC1 scores for exploration and boldness with difference scores calculated during the mate-choice

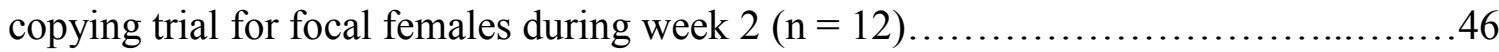




\section{LIST OF FIGURES}

Figure 1. Schematic lateral oblique view of the experimental apparatus for quantifying the exploratory behaviour of a focal female guppy in a novel environment (open zone). Plastic plants were either red or green, and their colour as well as their position was alternated between repeated trials. The experimental compartment is separated from the refuge by an opaque Plexiglas partition, which was fitted with a sliding opaque Plexiglas

door.

Figure 2. Schematic lateral oblique view of the experimental apparatus for quantifying the boldness behaviour of a female guppy when faced with a simulated threat of predation (using a predator model). The clear container in the smaller holding compartment contains one female guppy as a potential shoal mate for the focal test female. The pike cichlid model is shown suspended in the water column of a separate smaller aquarium located at the opposite end of the testing compartment from the holding compartment. The experimental compartment is separated from the refuge by an opaque Plexiglas partition fitted with a removable opaque Plexiglas door. Dotted lines drawn at 5-cm intervals on the front and back panes of the experimental aquarium aided in the recording of focal fish position during a trial, with zone 12 being closest to the predator model and zone 1 being closest to the refuge

Figure 3. Digital photograph of the pike cichlid model $(18 \mathrm{~cm}$, total length) used to test the boldness level of individual guppies. .18 
Figure 4. Schematic top view of the experimental apparatus used for testing mate-choice copying, showing each consecutive phase of the experiment. The central aquarium holds the focal test female (F) and each of the two end compartments hold a stimulus male and, depending on the phase, a model female (M) and pseudo-model female (PM), respectively. The central circle during Phase 2 represents a removable clear Plexiglas cylinder, in which the focal female is placed temporarily. The dotted line inside each end compartment represents a removable clear Plexiglas partition that allows the compartment to be open or divided in half, the thick black line denotes a removable opaque screen, and the stippled lines inside the central aquarium demarcate the $10-\mathrm{cm}$ wide preference zones...................................................22

Figure 5. Repeatability (R) of PC1 scores for exploratory behaviour in the two repeated trials $(\mathrm{n}=30)$

Figure 6. Repeatability (R) of PC1 scores for boldness in the two repeated trials $(\mathrm{n}=30)$

Figure 7. Pearson correlation (r) of PC1 scores for exploratory behaviour and boldness for week 1 (a) and week 2 (b) 36

Figure 8. Female mating preference after viewing the preferred male in Phase 1 sexually interacting with a model female (Experimental) or in the absence of a model female (Control). A negative value indicates that focal females decreased their original preference in Phase 3. Box plots show the twenty-fifth, fiftieth (median) and seventy-fifth percentiles, with the whiskers indicating minimum and maximum values .38 
Figure 9. Repeatability (R) of mate-choice copying tendency as measured by difference scores (the proportion of time spent near the initially-preferred male in Phase 3 minus the proportion of time near the initially-preferred male in Phase 1) in the two repeated trials

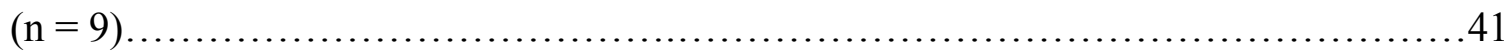




\section{LIST OF APPENDICES}

APPENDIX I - Ethovision software validation .64

Table 1. Measures of time spent in the open zone (s) and time spent moving while in the open zone (s) when recording manually using a stopwatch, compared with Ethovision XT video-analysis system. Each measure is based on a 300-second sample of each video clip

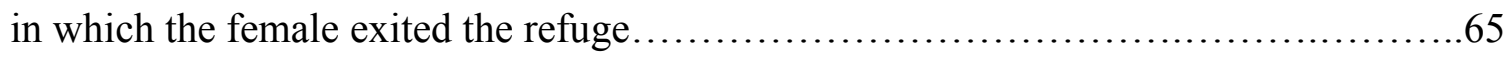

APPENDIX II - Results of Principal Component Analyses............................66

Table 1. Principal Component Analysis for correlated variables demonstrating

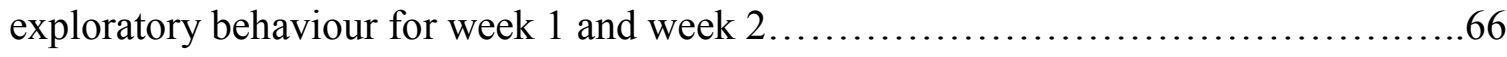
Table 2. Principal Component Analysis for correlated variables demonstrating boldness

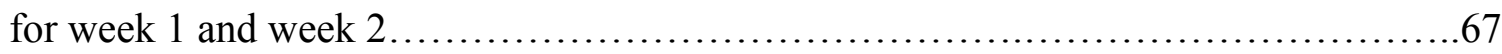

Table 3. Principal Component Analysis for correlated variables demonstrating exploratory behaviour and boldness for week 1 for females with successful mate-choice

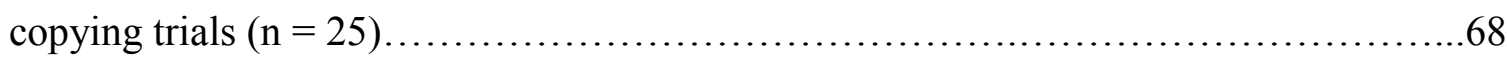

Table 4. Principal Component Analysis for correlated variables demonstrating exploratory behaviour and boldness for week 2 for females with successful mate-choice

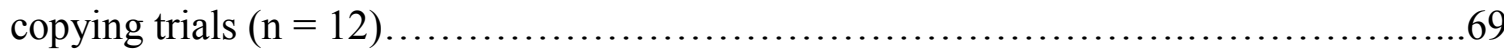


Table 5. Eigenvalues for behavioural measures for PC1 scores calculated for a) exploratory behaviour in a novel environment $(n=30$ for both weeks), b) boldness in the face of predation ( $\mathrm{n}=30$ for both weeks), c) exploratory behaviour in a novel environment for females with successful mate-choice copying trials $(n=25$ week 1, 12 week 2), and d) boldness in the face of predation for females with successful mate-choice

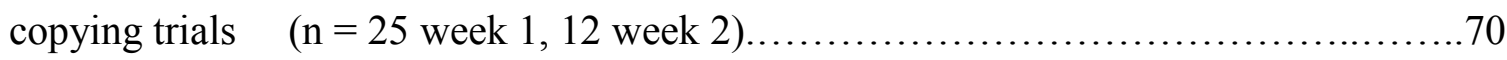




\section{INTRODUCTION}

\section{Animal personality}

Consistent differences in behaviour among individuals in a population are generally referred to as animal temperament or personality traits (Réale et al., 2007; Webster and Ward, 2010). Animal personality has been of particular interest to behavioural ecologists in recent years (Réale et al., 2007; Kurvers et al., 2010; Webster and Ward, 2010). Taxonomically diverse animals, including humans, exhibit distinct personality traits (e.g. Garcia-Sevilla, 1984; Eysenck and Eysenck, 1985; Réale et al., 2007) and such traits can be heritable and have fitness consequences (Dingemanse and Réale, 2005; Réale et al., 2007). For example, individual personality traits may influence reproductive success (Boon et al., 2007), dispersal (Dingemanse et al., 2003), and interspecific competition (Webster et al., 2009), among other phenomena.

Personality traits can be measured in a variety of ways (Réale et al., 2007), including risk taking behaviour or boldness towards predators (e.g. Dugatkin and Godin, 1992a,b; Godin and Davis, 1995; Godin and Dugatkin, 1996), general activity (e.g. Wilson and Godin, 2009), exploration of a novel environment (e.g. Wilson and Godin, 2009; Jones and Godin, 2010) and neophobia (avoidance of novel objects; Jones and Godin, 2010). There has been much debate about how to properly define various animal personality traits. For example, boldness is one of the most frequently measured personality traits (Conrad et al., 2011), and yet there seems to be no general consensus about how to operationally define it (Carter et al., 2013). Some researchers consider boldness to be risk-taking behaviour in a novel situation (Coleman and Wilson, 1998; Toms et al., 2010), whereas others define boldness as risk-taking behaviour without the 
context of novel stimuli (Réale et al., 2007). For research purposes, it is important to clearly define the personality trait of interest so as not to create further confusion, as well as to measure multiple variables for one trait (Carter et al., 2013). Through the use of data reduction techniques, such as Principal Component Analysis (PCA) or factor analysis, multiple variables can be collapsed into one explanatory component to characterize a personality trait and facilitate its interpretation (Carter et al., 2013).

Consistent personality traits have been observed in male guppies (Poecilia reticulata) from a feral population of unknown origin in Russia. Budaev (1997) reported two independent dimensions of personality involving novel situations, which he referred to as Activity Exploration or Approach (i.e. being either active or passive) and Fear Avoidance (i.e. being either bold or fearful). Consistent individual personality traits have also been observed in other species of fish, including the Midas cichlid, Cichlasoma citrinellum (Francis, 1990), convict cichlid, Amatitlania nigrofasciata (Budaev et al., 1999; Jones and Godin, 2010), brown trout, Salmo trutta (Adriaenssens and Johnsson, 2012), and pumpkinseed sunfish, Lepomis gibbosus (Coleman and Wilson, 1998).

\section{Social information and social learning}

Although several personality traits in animals are known to be consistent over time (i.e. repeatable) within and between contexts (refs cited above), the extent to which such traits can be influenced by learning opportunities remains poorly understood. Learning refers to a behaviour that is modified over time as a result of experience (Godin, 2010) and it allows for adaptive behavioural plasticity in individuals. There are two main types of information that an animal can gather. Personal information is obtained through direct interaction with the animal's environment and usually involves a process of trial 
and error (Danchin et al., 2004). A second form of information is social information, whereby an individual obtains information about its environment from observing the behaviour of other individuals and then is able to use this information to modify its own behaviour (Danchin et al., 2004; Godin, 2010). The use of personal information is particularly common when migrating between habitats or when moving through a current habitat (Dall et al., 2005) and animals are able to use a variety of environmental cues, such as the sun, the stars and environmental landmarks to help them find their way (Grocott, 2003). Learning through the use of personal information can be beneficial to an animal because in nature, where the environment is constantly changing, the use of personal information likely ensures that an animal is getting accurate, up-to-date, reliable information (Galef, 2009). However, acquiring personal information can also be quite costly to an individual. For example, in order to locate the most suitable habitat, an individual would have to search among available habitats within its home range, using up much of its energy reserves (Kendal et al., 2005) and render the animal susceptible to both predation and environmental dangers (Galef, 2009). Alternatively, the acquisition and use of social information is generally less costly, but may not necessarily provide updated and reliable information about the individual's environment (Kendal et al., 2005; Galef, 2009).

Social learning occurs when an animal's own behaviour is modified as a result of acquiring and using social information, obtained by directly observing the behaviour of others (Danchin et al., 2004; Godin, 2010). The individuals whose behaviours are being observed are often termed "demonstrators" or "models", and the focal individual that learns as a result is termed the "observer" (Heyes, 1994). Social learning has been observed in a variety of animal taxa, including insects (e.g. Coolen et al., 2005), fishes 
(e.g. Brown and Laland, 2001; Godin, 2010), birds (e.g. Johanessen et al., 2006), and mammals (e.g. Kubinyi et al., 2009). Many behaviours exhibited by fishes such as antipredator behaviour, foraging and mate choice can have a learned component (Brown and Laland, 2003; Godin, 2010). Since obtaining personal information comes with costs (Kendal et al., 2005; Galef, 2009), learning through the use of social information can be a relatively safer alternative (Galef, 2009). However, when observers choose to rely on social information, they run the risk of acquiring inaccurate, or out-of-date information, especially in a changing environment (Galef, 2009). Opting to use social information instead of personal information in a given context typically reflects an individual tradeoff between ensuring the accuracy of information obtained and the cost of obtaining such information (Giraldeau et al., 2002; Kendal et al., 2005).

Several studies have shown that the mate preferences of individual animals are not necessarily fixed, but rather can be influenced by their social experiences (e.g. Dugatkin and Godin, 1992c; Westneat et al., 2000; Godin et al., 2005; Godin, 2010). Social information has been found to influence mating preferences in a variety of fish species, including guppies (Dugatkin and Godin, 1992c; Dugatkin et al., 2003), mollies, Poecilia latipinna (Schlupp et al., 1994; Schlupp and Ryan, 1997), gobies, Pomatoschistus microps (Reynolds and Jones, 1999), and Japanese medaka, Oryzias latipes (Grant and Green, 1996), as well as in other taxa such as birds (Galef and White, 1998) and mammals (Gibson and Höglund, 1989).

One example of this form of social learning is female mate-choice copying, whereby a focal female is more likely to choose a male that she has observed mating or consorting recently with a nearby female (= 'model' female) than if no other female was present (Pruett-Jones, 1992). Mate-choice copying is an alternative, socially-mediated 
mate choice strategy (Galef and White, 2000; Westneat et al., 2000) and can in some instances override mating preferences that may be genetically determined (Dugatkin, 1996). As with any mating decision, mate-choice copying is associated with costs and benefits. Potential costs to mate-choice copying include: (i) an increased predation risk by being in a group for an extended period of time (i.e. increased conspicuousness); (ii) by choosing to copy, a focal female runs the risk that the model female could be conveying inaccurate information about the quality of the male; and (iii) because the male would have just mated with the model female, there is a risk of sperm depletion that could result in a decreased probability of the female's eggs being fertilized (Godin, 2010). On the other hand, potential benefits include: (i) less time spent searching for and assessing potential mates, and (ii) often a more accurate assessment of the chosen mate, especially when that can be difficult for the female to determine herself if the potential males appear to be very similar in body length and coloration (Godin, 2010).

When a female mate-choice copies, she is learning about available males by watching other females, and thus uses socially-acquired information to make a mating decision (Westneat et al., 2000; Witte and Massmann, 2003). A female's tendency to mate-choice copy can therefore be used as a proxy measure of her likelihood of using social information in making mating decisions. Although mating preferences of female guppies have been shown to be repeatable (Godin and Dugatkin, 1995; Brooks, 1996; Kodric-Brown and Nicoletto, 1997), and although it has been demonstrated in the past that mate-choice copying is not repeatable when the same pair of males is repeatedly used (Brooks, 1996), it appears that the repeatability of mate-choice copying tendency (with a different pair of males used) has not yet been tested. 


\section{Linking personality traits and social learning tendency - behavioural syndromes}

Consistent behavioural traits of individuals can be correlated with each other, thus constituting a suite of inter-correlated behaviours referred to as a behavioural syndrome (Sih et al., 2004a; Sih and Bell, 2008). Understanding the ecological and evolutionary implications of behavioural syndromes has been of considerable interest recently (Sih et al., 2004b; Sih and Bell, 2008). Behavioural syndromes offer an explanation for some behaviours that may appear maladaptive in certain contexts; for example, an individual that is highly aggressive towards its offspring, or highly active when predators are nearby, would seem maladaptive (Johnson and Sih, 2005). Behavioural syndromes may also explain the maintenance of individual variation in behaviour types or personality within populations (Sih et al., 2004a). In this context, characterizing and understanding the relationships between individual personality traits and other fitness-enhancing behaviours, such as predator avoidance (Jones and Godin, 2010) and mating (Godin and Dugatkin, 1996; Schuett et al., 2011), is particularly important. In particular, current knowledge of potential links between personality traits and the use of social information in behavioural decision making is generally lacking.

Where behaviours are not inter-correlated across contexts, it can be said that an individual is exhibiting behavioural flexibility (DeWitt et al., 1998). Behavioural phenotypes are among the most easily altered phenotypes (Foster and Sih, 2013), and because environments are rapidly changing nowadays, species have to cope with stressors such as climate change, invasive species, pollution, and habitats that are being destroyed by humans or converted to agricultural or urban areas (Snell-Rood, 2013). In these cases, a species that lacks the ability to adapt its behaviour to the changing ambient environment is likely to demonstrate inappropriate or maladaptive behaviours, which could cause 
population decline or even extinction (Schlaepfer et al., 2002). Adaptive shifts in behaviour have been suggested to help a population survive in novel environments until selection could act to increase the population's fitness (Foster and Sih, 2013).

\section{Thesis objective and predictions under test}

The general objective of my thesis research is to investigate the potential link or syndrome between two personality traits (namely, exploration of a novel environment and boldness towards predators) of individuals and their tendency to mate-choice copy (a form of social learning) in a sexual context, using the Trinidadian guppy as a model study system. Specifically, the aim is to answer the following questions: (i) are the aforementioned two measures of personality repeatable in (virgin) female guppies? (ii) Is the exploratory tendency of individuals in a novel environment correlated with their boldness in the face of a potential threat of predation (i.e. tendency to inspect a fish predator model), such that a behavioural syndrome exists? (iii) Is mate-choice copying behaviour a repeatable behaviour? And, (iv) are consistently more exploratory and bold females more or less likely to mate-choice copy when given the opportunity to do so? Although many studies have investigated mate-choice copying (e.g. Westneat et al., 2000; Godin, 2010), to my knowledge there exists no research on the potential link between personality traits and the use of social information in making mate-choice decisions.

Here, I tested the prediction that females who are more exploratory when introduced into a novel environment would also tend to be bolder when faced with a potential predation threat, as is the case for bluegill sunfish, Lepomis macrochirus (Wilson and Godin, 2009). Previous studies examining an individual's likelihood of 
using social information have reported conflicting results. A study on three-spined sticklebacks (Gasterosteus aculeatus) found that variation in boldness among individuals did not predict an individual's use of social information (Harcourt et al., 2010). In contrast, three-spined sticklebacks that were more exploratory in a novel environment relied on social information from demonstrators in navigating a maze more than those who were less exploratory (Nomakuchi et al., 2009). Similarly, captive great tits (Parus major) that were more exploratory copied a demonstrator's food preference more frequently than those who were less exploratory, when given the opportunity to use social information (Marchetti and Drent, 2000). On the contrary, a later study on great tits found that more exploratory birds used social information and cues in response to being mildly startled significantly less than those that were less exploratory, but this was only true for males (van Oers et al., 2005). Similarly, a study investigating only boldness and social information use in barnacle geese (Branta leucopsis) found that bolder male and female geese used social information less frequently in a foraging context than more timid conspecifics (Kurvers et al., 2010).

Based on these past findings, it was difficult to form predictions. Three alternative relationships between two personality traits (boldness and exploration) and mate-choice copying tendency are possible: (i) no relationship exists; (ii) bolder and more exploratory female guppies would be less likely to mate-choice copy when given the opportunity to do so than more timid and less exploratory individuals; or, (iii) bolder and more exploratory females would be more likely to mate-choice copy than more timid and less exploratory individuals. 


\section{METHODS}

\section{Study species and holding conditions}

The Trinidadian guppy was used as a model study system for the following reasons. This species is an important model for the study of sexual selection and evolution, and much is known about its evolutionary and behavioural ecology (Houde, 1997; Magurran, 2005). Like all poeciliid fishes, fertilization in the guppy is internal and young are born live, fully developed and mobile. Guppies are ideal for manipulative experiments in the laboratory because of their short generation time (as little as two months from egg fertilization to sexual maturity), large brood sizes ( $\geq 20$ young for the largest females), and ease of husbandry (Houde, 1997). Furthermore, females tend to be the choosier sex, which makes them ideal for mate-choice experiments (Houde, 1997), while predator inspection (e.g. Dugatkin and Godin, 1992a; Godin and Davis, 1995; Godin and Dugatkin, 1996) and mate-choice copying behaviours (e.g. Dugatkin and Godin, 1992c; Godin et al., 2005) have been previously described for this species.

The guppies used in this experiment were lab-born and raised $\mathrm{F}_{1}$ and $\mathrm{F}_{2}$ descendants of wild-caught guppies from the Upper Aripo River (Naranjo tributary) in Trinidad, a low-predation population. Prior to being used in experimental trials, the fish were held at low densities in 20-L glass aquaria filled with filtered and aged tap water maintained at $24-26^{\circ} \mathrm{C}$ and exposed to overhead fluorescent illumination on a $13 \mathrm{~h} \mathrm{~L}: 11$ h D illumination cycle. The fish were fed ad libitum both commercial fish flakes and live brine shrimp nauplii (Artemia salina) 2-3 times daily in their holding tanks. 


\section{Experimental protocols}

This study comprised three inter-related parts (see below). The basic research protocol involved testing each of 36 virgin focal females twice (to test for repeatability or consistency of behaviour; cf. Bell et al., 2009) for each of three behavioural measures (see below). Virgin females were used because they are known to be highly sexually responsive to males (Houde, 1997). They were obtained following their birth by physically isolating them from males just before they reached full sexual maturity (visually assessed by the appearance of the gonopodium and (or) body coloration in males and the shape of the anal fin and a dark ovipore spot in females; Houde, 1997). Identified males and females were housed in separate adjacent aquaria in view of each other to ensure that they were not completely naïve of the opposite sex before testing. Naïve virgin females can be overly responsive to males and it is thought that they may be less choosy than experienced females reared in the presence of males (Houde, 1997).

\section{Part A: Quantifying personality traits and their repeatability}

Focal females were individually tested for two ecologically important personality traits, exploratory behaviour in a novel environment and boldness in the face of a simulated predation threat, on the same day, with the order of the personality traits measured alternated between test subjects. To quantify the repeatability of these personality traits, each female was similarly re-tested one week later, with the order of the personality trait measured reversed, such that if a female was tested first for exploration in the morning and boldness in the afternoon on week 1 , then she was tested for boldness in the morning and exploration in the afternoon on week 2. Although a total 
of 36 focal female guppies were initially tested, six of them died prior to being tested in week 2, thus yielding a total sample size of 36 for week 1 and 30 for week 2 .

\section{i) Repeatability of personality traits}

Personality trait 1: Exploratory behaviour in a novel environment

Exploratory behaviour of focal female guppies was tested by exposing them to a novel environment and by quantifying the time taken to exit a refuge and enter the novel environment (= latency time), the distance moved, the time spent moving, and the time spent in the open zone (and not in the refuge) during a standardized period. The experimental method used closely follows that of Jones and Godin (2010).

The experimental apparatus consisted of an aquarium $(75 \times 30 \times 28 \mathrm{~cm}, \mathrm{~L} \times \mathrm{W}$ x $\mathrm{H}$; water depth $=25 \mathrm{~cm}$ ) divided into two compartments (a small holding compartment, $\mathrm{L}$ $=15 \mathrm{~cm}$, and a larger novel compartment, $\mathrm{L}=60 \mathrm{~cm}$ ) with an opaque Plexiglas partition, equipped with a sliding door and illuminated overhead with fluorescent lighting (Fig. 1). Both compartments contained a layer of small gravel on the bottom, and were filled with aerated aged tap water maintained at $24-26^{\circ} \mathrm{C}$. Furthermore, the larger novel compartment contained three plastic plants anchored to the substratum, which were either green or red (plant colour and placement were alternated between the two repeated trials on each test fish, with the order of presentation randomized, to mitigate potential habituation to the environment between repeated trials). The back and side walls of the aquarium were covered externally with tan paper to reduce external disturbances and to provide a uniform background. The behaviour of the fish was filmed through the open 
side of the aquarium, using a Sony VIXIA HF M400 video camera, from behind a blind covering both the camera as well as the entire apparatus.

For each trial, a focal female guppy was introduced into the refuge and left undisturbed to acclimatize for $30 \mathrm{~min}$. Following this period, the trial began by remotely raising (using a pulley system) the sliding door of the refuge compartment (Fig. 1), thereby allowing the female to enter the larger compartment (= the novel environment) and freely explore it. The fish was allowed up to $20 \mathrm{~min}$ to exit the refuge. Upon exiting the refuge and entering the novel environment, the female's behaviour was recorded for $15 \mathrm{~min}$. If the fish did not leave the refuge compartment within $20 \mathrm{~min}$, then a time of 1200 seconds was given for latency to exit the refuge and a score of 0 was given for each of the other three behavioural variables. For each individual test female, I recorded each of the four measures of exploratory behaviour as described above. The behaviour of the focal females was quantified via playback of the videotapes using Ethovision XT videoanalysis system (Noldus Information technology, Leesburg, VA). This method of analysis was found to be highly reliable when compared with manual measures of total time spent swimming in the open zone and total time spent in the open zone (see Appendix I).

At the end of each trial, the individual focal female was temporarily placed in a small $(30 \times 15 \times 20 \mathrm{~cm}, \mathrm{~L} \times \mathrm{W} \times \mathrm{H})$ aquarium and similarly re-tested for her exploratory behaviour one week later.

\section{Statistical analyses}

Only those focal females who survived to week $2(n=30)$ were used for analysis. During week 1, 10 of the 30 females tested failed to leave the refuge and so received 


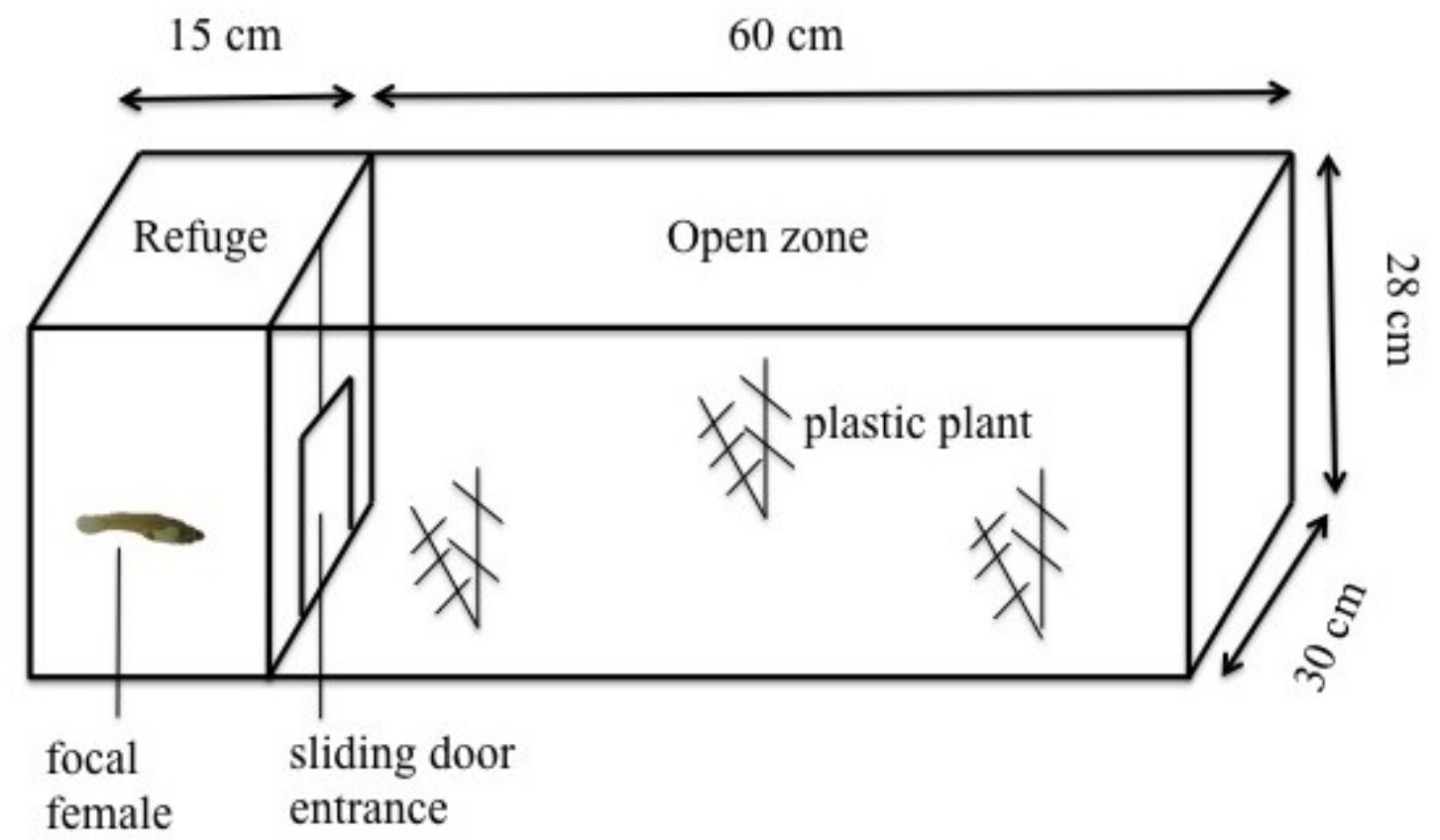

Figure 1. Schematic lateral oblique view of the experimental apparatus for quantifying the exploratory behaviour of a focal female guppy in a novel environment (open zone). Plastic plants were either red or green, and their colour as well as their position was alternated between repeated trials. The experimental compartment is separated from the refuge by an opaque Plexiglas partition, which was fitted with a sliding opaque Plexiglas door. 
maximum latency scores of $1200 \mathrm{~s}$ and scores of 0 for total distance moved, time moving in the open zone, and total time spent in the open zone. During week 2, 12 of the 30 females tested failed to leave the refuge and received scores as previously described. Statistical tests were conducted separately for week 1 and week 2 . Prior to statistical analysis, the distribution of each of these four behavioural variables was tested for normality. Since these data were not normally distributed, they were $\log _{10}$-transformed before analysis. A correlation matrix for the four variables was first obtained to establish whether an exploratory behavioural syndrome existed. Because the four variables were significantly inter-correlated (see Results), they were collapsed into a single composite score for exploratory behaviour using Principal Component Analysis (PCA). This analysis places each focal female along a PCA axis (continuum) ranging from weakly to highly exploratory individuals. The correlation matrix and PCA were performed using SPSS v. 21 statistical software (SPSS Inc., 2012).

To ensure the variable loadings (eigenvalues) were similar when calculating the first principal component (PC1) scores for both week 1 and week 2 data, product moment correlations were calculated. Since there were a large number of females who did not leave the refuge after $20 \mathrm{~min}$, the frequency of females who left the refuge was compared with the frequency of females who did not leave the refuge in both week 1 and week 2 using the G-test.

An estimate of the repeatability of exploratory behaviour (as measured using PCA scores) of individual females in repeated test 1 and test 2 was calculated using generalized linear mixed-effects models (GLMMs) suitable for non-Gaussian data (i.e. data that are not normally distributed) using the 'rptR' package ('rpt.poisGLMM.multi' function; Nakagawa and Schielzeth, 2010) developed in R software. In the model, focal 
female identity was assigned as a grouping random factor (Nakagawa and Schielzeth, 2010). For each estimated repeatability (R) coefficient, the associated calculated standard error (SE) and 95\% confidence interval (CI) are provided. Additionally, the repeatability of exploratory behaviour of just those individuals who exited the refuge in both week 1 and week $2(\mathrm{n}=13)$ was calculated, using the Restricted Maximum Likelihood (REML) method using linear mixed-effects models (LMMs) suitable for Gaussian (normally distributed) data using the 'rptR' package ('rpt.remlLMM' function; Nakagawa and Schielzeth, 2010) developed in R software (R Development Core Team, 2012).

\section{Personality trait 2: Boldness under predation threat}

The shyness-boldness of the same focal females was tested by exposing each individual to an environment containing a simulated threat of predation (presence of a model pike cichlid predator) and quantifying their inspection or approach behaviour towards the predator model (cf. Dugatkin and Godin, 1992a; Godin and Davis, 1995), as a measure of risk-taking behaviour or boldness (Dugatkin and Godin, 1992b). In approaching the predator model, the focal fish necessarily leaves the apparent relative safety of a nearby conspecific shoal (cf. Krause and Ruxton, 2002) to take the potential risk of approaching a potential predatory threat at a distance (Dugatkin and Godin, 1992b). The pike cichlid (Crenicichla spp.) is a major natural predator of the guppy in Trinidad (Houde, 1997; Magurran, 2005). The experimental method used was adapted from Jones and Godin (2010). In general, fishes respond behaviourally to realistic models in qualitatively similar ways as they do to their live natural fish predators (e.g. Magurran and Girling, 1986). 
The experimental apparatus consisted of an aquarium $(75 \times 30 \times 28 \mathrm{~cm}, \mathrm{~L} \times \mathrm{W}$ x $\mathrm{H}$; water depth $=15 \mathrm{~cm}$ ) divided into two compartments (a smaller holding compartment, $\mathrm{L}=15 \mathrm{~cm}$ and a larger test compartment, $\mathrm{L}=60 \mathrm{~cm}$ ) with an opaque removable Plexiglas partition, and illuminated overhead with fluorescent lighting (Fig. 2). Both compartments contained a layer of small gravel on the bottom, and were filled with aerated aged tap water maintained at $24-26^{\circ} \mathrm{C}$. One female conspecific was placed in a clear plastic, perforated container in one of the corners of the holding compartment to serve as a potential shoaling companion for the test female. The predator model is a realistically constructed and painted cast model (18 cm total length) of a pike cichlid (Fig. $3)$, and was suspended broadside in the water column ( $5 \mathrm{~cm}$ above the substratum) with monofilament lines in a separate aquarium $(13 \times 30 \times 20 \mathrm{~cm}, \mathrm{~L} \times \mathrm{W} \times \mathrm{H})$, placed immediately adjacent to the test aquarium and at the end of the test aquarium opposite from the holding compartment (Fig. 2). The back and side walls of both the test aquarium and the predator aquarium were covered externally with tan paper to reduce external disturbances and to provide a uniform background. The behaviour of the fish was observed through the open side of the aquarium and from behind a blind covering the entire apparatus. For each trial, before the predator model was placed into the predator aquarium, a focal female guppy was placed into the test compartment and was left undisturbed for $30 \mathrm{~min}$ to swim freely. This acted as a familiarization phase, so that the environment was not entirely novel upon commencement of the trial. The fish was then gently dip-netted and placed inside the refuge compartment (with the restrained companion fish, and with the refuge door closed) and left undisturbed to acclimatize for a further 30 min. Following this period, the trial began by remotely raising (using a pulley 


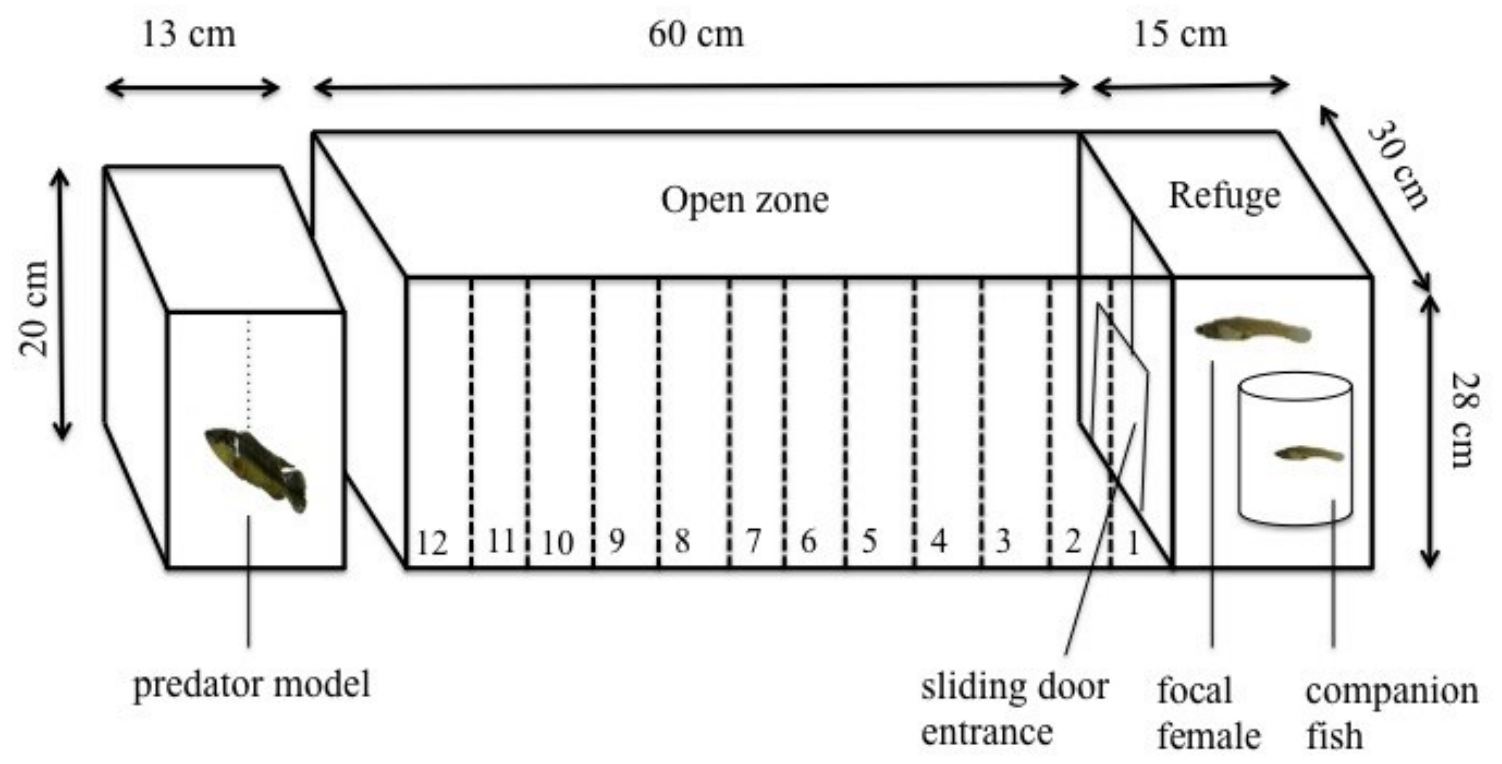

Figure 2. Schematic lateral oblique view of the experimental apparatus for quantifying the boldness behaviour of a female guppy when faced with a simulated threat of predation (using a predator model). The clear container in the smaller holding compartment contains one female guppy as a potential shoal mate for the focal test female. The pike cichlid model is shown suspended in the water column of a separate smaller aquarium located at the opposite end of the testing compartment from the holding compartment. The experimental compartment is separated from the refuge by an opaque Plexiglas partition fitted with a removable opaque Plexiglas door. Dotted lines drawn at 5 -cm intervals on the front and back panes of the experimental aquarium aided in the recording of focal fish position during a trial, with zone 12 being closest to the predator model and zone 1 being closest to the refuge. 


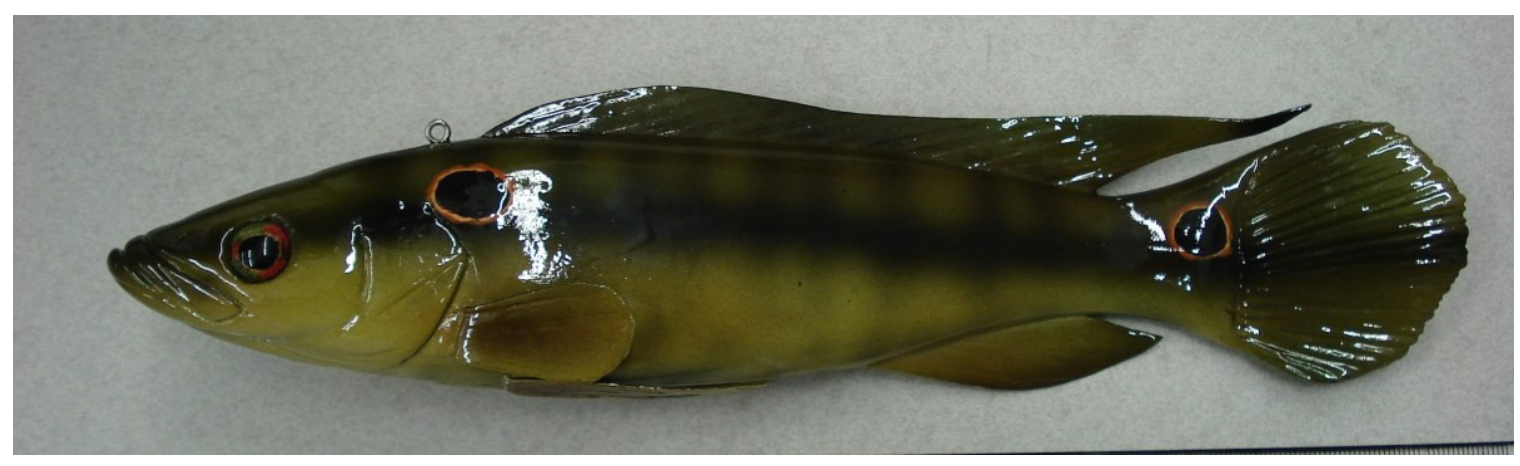

Figure 3. Digital photograph of the pike cichlid model $(18 \mathrm{~cm}$, total length) used to test the boldness level of individual guppies. 
system) the refuge door, thus allowing the focal female to view and approach the predator model at the opposite end of the aquarium. The fish was given $20 \mathrm{~min}$ to leave the refuge. If the fish did not leave the refuge compartment within $20 \mathrm{~min}$, then a time of 1200 seconds was given for latency to exit the refuge and a score of 0 was given for the boldness variables (see below). If the focal female entered the open zone, then her behaviour was recorded for 15 min. For each individual test female, I recorded using JWatcher (Blumstein and Daniel, 2007): (i) latency to leave the refuge; (ii) frequency of discrete bouts of predator inspection/approach behaviour (cf. Dugatkin and Godin, 1992a; Godin and Davis, 1995); (iii) the duration of each inspection bout (the sum of which equals total time spent inspecting the predator model); and (iv) the median minimum distance approached to the predator model.

At the end of each trial, the focal female was temporarily placed in a separate small $(30 \times 15 \times 20 \mathrm{~cm}, \mathrm{~L} \times \mathrm{W} \times \mathrm{H})$ aquarium and similarly re-tested for her boldness one week later.

\section{Statistical analyses}

Only those focal females who survived to week $2(n=30)$ were used for analysis. During week 1, 18 of the 30 focal females tested failed to leave the refuge and so received maximum latency scores of $1200 \mathrm{~s}$ and scores of 0 for frequency of inspection bouts, total time inspecting, and median minimum approach distance. During week 2, 20 of the 30 focal females tested failed to leave the refuge and received scores as previously described. Statistical tests were conducted separately for week 1 and week 2 . Prior to statistical analysis, the distribution of each of these four behavioural variables was tested for normality. Since these data were not normally distributed, they were $\log _{10^{-}}$ 
transformed before analysis. A correlation matrix for the four variables was first obtained to establish whether a boldness behavioural syndrome exists. Because the four boldness variables were significantly inter-correlated (see Results), they were collapsed into a single composite score for boldness behaviour using PCA. The correlation matrix and PCA were performed using SPSS v.21 statistical software.

An estimate of the repeatability of boldness under the threat of predation (as measured using PCA scores) of individual females in repeated test 1 and test 2 was calculated using GLMMs suitable for non-Gaussian data using the 'rptR' package ('rpt.poisGLMM.multi' function; Nakagawa and Schielzeth, 2010) developed in R software. To ensure the variable loadings (eigenvalues) were similar when calculating PC1 scores for both week 1 and week 2 data, product moment correlations were calculated. Since there were a large number of females who did not leave the refuge after $20 \mathrm{~min}$, the frequency of females who left the refuge was compared with the frequency of females who did not leave the refuge in both week 1 and week 2 using the G-test. Additionally, the repeatability of boldness under the threat of predation of only those individuals who left the refuge in both week 1 and week $2(n=6)$ was calculated using the REML method using LMMs suitable for Gaussian (normally distributed) data using the 'rptR' package ('rpt.remlLMM' function; Nakagawa and Schielzeth, 2010) developed in R software. In the model, focal female identity was assigned as a grouping random factor (Nakagawa and Schielzeth, 2010). For each estimated repeatability (R) coefficient, the associated calculated standard error (SE) and 95\% confidence interval (CI) are provided. 


\section{ii) Correlation between exploratory and boldness behaviours}

The relationship between the exploratory and boldness behaviours expressed by individual female guppies (measured by PC1 scores) was characterized using the Pearson correlation test (cf. Jones and Godin, 2010) for both week 1 and week 2 separately using R software. Only those females who survived to week $2(n=30)$ were used for analysis.

\section{Part B: Social information use and mate-choice copying behaviour i) Mate-choice copying tendency}

Several studies by Godin, Dugatkin and colleagues have previously demonstrated that adult female Trinidadian guppies can copy the observed apparent mate choice of other nearby females when given the opportunity to do so, but that there exists interindividual variability in the magnitude of their mate-copying tendency (e.g. Dugatkin, 1992; Dugatkin and Godin, 1992c, 1993; Godin et al., 2005; Godin and Hair, 2009). Here, the initial mating preference and mate-choice copying behaviour of individual virgin female guppies originating from the Upper Aripo River was tested as follows.

\section{Assessing mating preferences}

The mating preference of individual focal females was quantified using a dichotomous mate-choice apparatus and standardized protocol similar to those described in Dugatkin and Godin (1992c) and Godin and Dugatkin (1995). The apparatus consisted of a central test aquarium $(40 \times 20 \times 25 \mathrm{~cm}, \mathrm{~L} \times \mathrm{W} \times \mathrm{H}$; water depth $=15 \mathrm{~cm})$, flanked by a clear Plexiglas container $(15 \times 20 \times 25 \mathrm{~cm}, \mathrm{~L} \times \mathrm{W} \times \mathrm{H})$ at either end (Fig. 4). Vertical lines drawn on the front and back walls of this aquarium delineated a10-cm wide 
a)
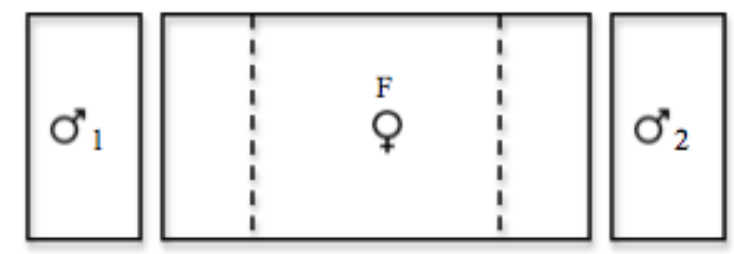

\section{Phase 1}

(preference test 1)

b)
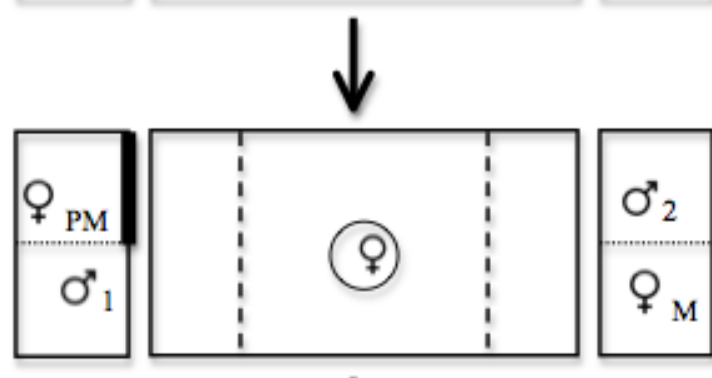

c)

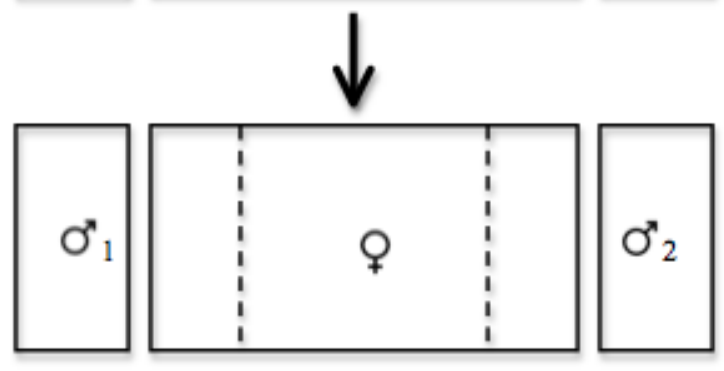

Phase 2

(viewing period copying opportunity)

\section{Phase 3}

(preference test 2)

Figure 4. Schematic top view of the experimental apparatus used for testing mate-choice copying, showing each consecutive phase of the experiment. The central aquarium holds the focal test female (F) and each of the two end compartments hold a stimulus male and, depending on the phase, a model female (M) and pseudo-model female (PM), respectively. The central circle during Phase 2 represents a removable clear Plexiglas cylinder, in which the focal female is placed temporarily. The dotted line inside each end compartment represents a removable clear Plexiglas partition that allows the compartment to be open or divided in half, the thick black line denotes a removable opaque screen, and the stippled lines inside the central aquarium demarcate the $10-\mathrm{cm}$ wide preference zones. 
preference zone adjacent to each end compartment. The back wall of the aquarium and three sides of the end compartments were covered externally with tan paper to minimize external disturbances and to provide a uniform background. Both the test aquarium and the end compartments contained a layer of small gravel on the bottom, and were filled with aerated aged tap water $\left(24-26^{\circ} \mathrm{C}\right)$ to a depth of $15 \mathrm{~cm}$. The entire apparatus was illuminated overhead by fluorescent lights and placed inside a blind. The behaviour of thefocal females was observed from behind the blind.

In a typical test, a focal female was allowed to 'choose' between two stimulus males, each located in one or the other of the paired end compartments. The initial assignment of the males to the end compartments was determined at random. Paired males were matched as closely as possible for standard body length and body coloration, so as to promote mate copying (cf. Dugatkin, 1996). The stimulus males were chosen from a holding aquarium different from that of the focal females to avoid any prior social familiarization that might bias female mate choice (e.g. Hughes et al., 1999). The amount of time the focal female spent in each end preference zone and facing $\left(0 \pm 90^{\circ}\right)$ the stimulus male was recorded during two consecutive 10-min tests (see below) as a proxy of her mating preference (e.g. Dugatkin and Godin, 1992c; Jeswiet and Godin, 2011).

\section{Assessing mate-choice copying}

Individual focal females were tested for their mate-choice copying tendency using the established choice-reversal method (Dugatkin and Godin, 1992c; Schlupp et al., 1994). A typical trial with any focal female consisted of three consecutive phases, as follows. Phase 1 tested for the initial mating preference of the focal female, in the absence of any copying opportunity. With the paired stimulus males in their respective 
end compartments and with the opaque partitions in place (blocking view into the end compartments), a focal female was initially placed in a clear Plexiglas cylinder $(7 \mathrm{~cm}$ in diameter) in the centre of the test aquarium and left undisturbed to acclimatize for $15 \mathrm{~min}$. The opaque partitions were then removed and the focal female was given 10 min to view the males in their respective compartments. Following this viewing period, the cylinder was lifted and the female was allowed to choose between the males (Fig. 4a). The amount of time the female spent in each preference zone was recorded for $10 \mathrm{~min}$, as described above. After this time had elapsed, the female was gently dip netted and returned to the central cylinder, and the opaque partitions returned into position to block the males from view. The female was given 2 min to re-acclimatize, during which time the positions of the end compartments holding the stimulus males were switched to control for any potential side bias of the focal female. The partitions were then raised, the female was released from the cylinder, and her preference was similarly recorded for another $10 \mathrm{~min}$. The focal female's mating preference was taken as the sum of the time spent near either stimulus male over 20 min (= two consecutive 10-min choice tests). If the focal female spent $\geq 55 \%$ of her time in the preference zone facing one of the males, then she was considered to have 'preferred' that particular male; time spent outside the male preference zones was not used to assess female mating preference (cf. Godin et al., 2005).

A trial was discontinued at the end of Phase 1, and excluded from further analysis, if either the focal female exhibited a side bias (defined as spending more than $80 \%$ of the time in one and the same preference zone over the two 10-min choice tests; Schlupp and Ryan, 1997; Dosen and Montgomerie, 2004), if each of the paired stimulus males was not sampled at least once during this phase of the trial, or if one male was not preferred by at least $55 \%$ of the time. These rigorous conservative criteria were applied to ensure that a 
focal female did in fact exhibit a preference and that she was aware of the presence of the two stimulus males.

Immediately following the initial preference test in Phase 1, the focal female was returned to the central cylinder and presented in Phase 2 with an opportunity to view the apparent mate choice of a demonstrator "model" female for the male that was not initially chosen in Phase 1 (Fig. 4b). Subsequently in Phase 3 (Fig. 4c), the focal female was retested to ascertain whether the initial mating preference (for one particular male, Phase 1) was altered after the female had observed the initially less-preferred stimulus male sexually interact with a model female (in Phase 2).

During Phase 2, the male end compartments were both divided in half by a transparent partition (Fig. 4b). With the opaque partitions in place and the female in the central cylinder, a model female was placed in the half-compartment adjacent to the male that was not initially preferred by the focal female. Based on previous studies (e.g. Dugatkin and Godin, 1992c; Briggs et al., 1996; Godin et al., 2005), it was expected that this male and model female would interact sexually (courtship behaviours exhibited by both sexes) across the clear partition separating them. To control for possible differential activity of the paired males, a 'pseudo-model female' was placed in the half-compartment next to the other male, but an opaque partition blocked the focal female's view of this stimulus female (so that only the male could be seen, but not the pseudo-model female interacting with him). The model, pseudo-model and focal females in a given trial were matched for body length. Once the stimulus females had been placed in the respective male end compartments, the opaque partitions were removed and the focal female was allowed to observe both males, as well as the model female, for $10 \mathrm{~min}$. The courtship behaviour expected to be shown by the model female and the male nearest her provided a 
staged opportunity for the focal female to see the model apparently 'choose' the male that was not initially preferred.

Following this viewing period (Phase 2), the opaque partitions were placed in position, and the model and pseudo-model females (as well as the clear partitions dividing the end compartments) removed from the end male compartments. The opaque partitions were then removed and the focal female released from the cylinder and allowed to choose between the males for a second time (Fig. 4c; Phase 3). The focal female's mating preference was similarly recorded over two consecutive 10-min periods, with the positions of the stimulus males switched between the two periods, as for Phase 1 .

A trial was discontinued at the end of Phase 3, and excluded from further analysis, if either the focal female exhibited a side bias (as defined above), or if each of the paired stimulus males were not sampled at least once during this phase of the trial.

If a focal female switched her initial mating preference after having observed a model female visually interact with the previously non-preferred male, then the female was deemed to have 'copied' the apparent mate choice of the model female (cf. Dugatkin and Godin, 1992c; Schlupp et al., 2004). To measure the magnitude of any such alteration in initial mating preference (= tendency to mate-choice copy), the percentage of time each focal female spent associating with the initially-preferred male in Phase 1 and Phase 3 were calculated separately. For each focal female, a difference score was then calculated for any change in mating preference between the matched preference tests [difference score $(\%)=$ the percentage of time spent near the initially-preferred male in Phase 3 minus the percentage of time near the initially-preferred male in Phase 1], following Jeswiet et al. (2011). A negative value denotes a decrease in the percentage of time a focal female spent with the initially-preferred male, and therefore an increased 
preference for the other male that was apparently chosen earlier by the model female (as a measure of the focal female's tendency to mate-choice copy, and therefore her tendency to use social information).

The mate-choice copying tendency of individual females was repeatedly ascertained (with same protocol described above), with the two repeated tests spaced one week apart (see below). During the first week, 11 of the 36 mate-choice copying trials had to be discarded ( $\mathrm{n}=25)$, while 17 of the 30 mate-choice copying trials had to be discarded during the second week $(\mathrm{n}=13)$. Furthermore, a chi-square test for the detection of outliers in a vector (Dixon, 1950), performed in R software, revealed one outlier in the data set from week $2\left(\chi^{2}=6.69, \mathrm{p}=0.009\right)$, which was excluded, bringing the total sample size to 12 .

\section{Control for mate-choice copying}

Although mate-choice copying has been observed in many populations of the Trinidadian guppy (e.g. Dugatkin and Godin, 1992c; Dugatkin et al., 2003; Godin et al., 2005), it has not yet been documented for the Upper Aripo River population. To control for other factors that could be causing a reversal in female mating preference, 20 additional virgin females were tested following the same procedure as described above, except that during the viewing period (Phase 2; Fig. 4b), there was no model female or pseudo-model female present in the male end compartments (and hence no copying opportunity present). 


\section{Statistical analyses}

The choice behaviour of focal females in the control trials (no model female present) was compared with that of females in the experimental trials (model female present) using the independent $t$-test. Mate-choice copying trials from week 1 and week 2 were combined $(\mathrm{n}=29)$. If a particular female had a successful trial during both weeks, the difference scores were averaged to yield one data point, ensuring statistical independence. Furthermore, a chi-square test for the detection of outliers in a vector (Dixon, 1950) revealed one outlier in the data set $\left(\chi^{2}=4.82, p=0.02\right)$, which was excluded, bringing the total sample size to 28 .

\section{ii) Repeatability of mate-choice copying}

After a focal female had been tested for her mate-choice copying tendency (i.e. at the end of Phase 3$)$ during week 1 , she was temporarily placed in a small $(30 \times 15 \times 20$ $\mathrm{cm}, \mathrm{L} \times \mathrm{W} \times \mathrm{H}$ ) aquarium and similarly re-tested for mate-choice copying tendency one week later (week 2). A different pair of stimulus males was used for the repeated test.

Owing to the aforementioned described criteria characterizing successful trials, only 9 of the 30 focal females had successful mate-choice copying trials for both week 1 and week 2. These 9 females thus comprised the data set for the estimation of the repeatability of mate-choice copying behaviour described below

\section{Statistical analyses}

At the end of the repeated trials, the focal females were lightly anaesthetized using MS-222 and their left side photographed. Their standard body length was measured from the digital pictures using ImageJ 1.45S. The body lengths of the focal female and 
model female for each trial were compared using the paired $t$-test using R software. An estimate of the repeatability of mate-choice copying tendency (as measured using the aforementioned difference scores) of individual females in repeated test 1 and test 2 was then calculated using an ANOVA-based method suitable for Gaussian (normally distributed) data using the 'rptR' package ('rpt.aov' function; Nakagawa and Schielzeth, 2010) developed in R software.

To control for any effects of difference in male body length or body coloration, the two stimulus males used in each trial were anaesthetized using MS-222 and photographed at the end of the trial. The areas of black and orange pigmentation on the left side of the body, excluding the fins, were calculated using ImageJ 1.45S (National Institutes of Health, USA) to obtain a colour score ([black area + orange area] / total body area) for each male. The colour scores of the paired stimulus males for each trial were compared using the paired $t$-test using $\mathrm{R}$ software.

\section{Part C: Linking personality traits and mate-choice copying tendency}

The relationship between each repeatable personality trait measure (i.e. exploration and boldness) and mate-choice copying tendency (i.e. preference difference score), as a measure of social information use, for individual female guppies was characterized using the Pearson correlation test (cf. Jones and Godin, 2010). To control for the potential confounding effect of the body size of focal females on behaviour, a general linear model (GLM) was constructed in R software with focal female standard body length and the two personality measures specified as fixed effects, and female mating preference difference scores (measure of mate-choice copying tendency) as the 
dependent variable (cf. Jones and Godin, 2010). This was done separately for both week 1 and week 2 .

\section{RESULTS}

\section{Part A: Personality traits and their repeatability}

\section{i) Repeatability of exploratory and boldness behaviours}

Personality trait 1: Exploratory behaviour in a novel environment

A correlation matrix for the exploration behavioural measures (latency to exit the refuge, total distance moved in the open zone, total time spent moving in the open zone, and total time spent in the open zone) revealed significant correlations between all four variables for both week 1 and week 2 (Table 1). Females who were quicker to exit the refuge (i.e. had a shorter latency time) spent more time in the open zone, moved a greater distance in the open zone, and spent more time moving in the open zone (as oppose to freezing, sensu Godin, 1997) than those who were slower to exit the refuge. These correlated variables were then collapsed into a single composite score (PC1) for exploratory behaviour using PCA, with the first component accounting for approximately $88 \%$ of the total variance for week 1 and $91 \%$ for week 2 (Appendix II - Table 1). Exploratory behaviour, as measured by PC1 scores, was not repeatable from week 1 to week $2(\mathrm{R}=0.11, \mathrm{SE}=0.15, \mathrm{CI}=0-0.47, \mathrm{p}=0.19 ;$ Fig. 5$)$. The proportion of focal females exiting the refuge within $20 \mathrm{~min}$ in week 1 did not differ significantly from that of week $2\left(\mathrm{G}_{1}=0.28, \mathrm{p}>0.5\right)$. When analyzing only those females who did exit the refuge in both weeks 1 and 2, their exploratory behaviour was similarly not repeatable 
Table 1. Correlation matrix using Pearson correlations (r) for measures of exploratory behaviour for week 1 and week 2 . All variables were normalized by $\log _{10}$ transformation prior to analysis. The correlations shown in boldface are statistically significant $(\mathrm{p}<0.0001)$

\section{Week 1}

\begin{tabular}{|c|c|c|c|c|}
\hline & $\begin{array}{l}\text { Latency to exit } \\
\text { refuge }(\mathrm{s})\end{array}$ & $\begin{array}{l}\text { Total distance } \\
\text { moved }(\mathrm{cm})\end{array}$ & $\begin{array}{l}\text { Time moving in } \\
\text { open zone }(\mathrm{s})\end{array}$ & $\begin{array}{l}\text { Time spent in } \\
\text { open zone (s) }\end{array}$ \\
\hline $\begin{array}{l}\text { Latency to exit } \\
\text { refuge }(\mathrm{s})\end{array}$ & 1.00 & -0.64 & -0.65 & -0.65 \\
\hline $\begin{array}{l}\text { Total distance } \\
\text { moved }(\mathrm{cm})\end{array}$ & & 1.00 & 0.99 & 0.99 \\
\hline $\begin{array}{l}\text { Time moving in } \\
\text { open zone (s) }\end{array}$ & & & 1.00 & 1.00 \\
\hline $\begin{array}{l}\text { Time spent in } \\
\text { open zone }(s)\end{array}$ & & & & 1.00 \\
\hline
\end{tabular}

\section{Week 2}

\begin{tabular}{|c|c|c|c|c|}
\hline & $\begin{array}{l}\text { Latency to exit } \\
\text { refuge (s) }\end{array}$ & $\begin{array}{c}\text { Total distance } \\
\text { moved }(\mathrm{cm})\end{array}$ & $\begin{array}{c}\text { Time moving in } \\
\text { open zone }(\mathrm{s})\end{array}$ & $\begin{array}{l}\text { Time spent in } \\
\text { open zone (s) }\end{array}$ \\
\hline $\begin{array}{l}\text { Latency to exit } \\
\text { refuge (s) }\end{array}$ & 1.00 & -0.75 & -0.75 & -0.75 \\
\hline $\begin{array}{l}\text { Total distance } \\
\text { moved }(\mathrm{cm})\end{array}$ & & 1.00 & 0.99 & 0.99 \\
\hline $\begin{array}{c}\text { Time moving in } \\
\text { open zone (s) }\end{array}$ & & & 1.00 & 0.99 \\
\hline $\begin{array}{l}\text { Time spent in } \\
\text { open zone (s) }\end{array}$ & & & & 1.00 \\
\hline
\end{tabular}




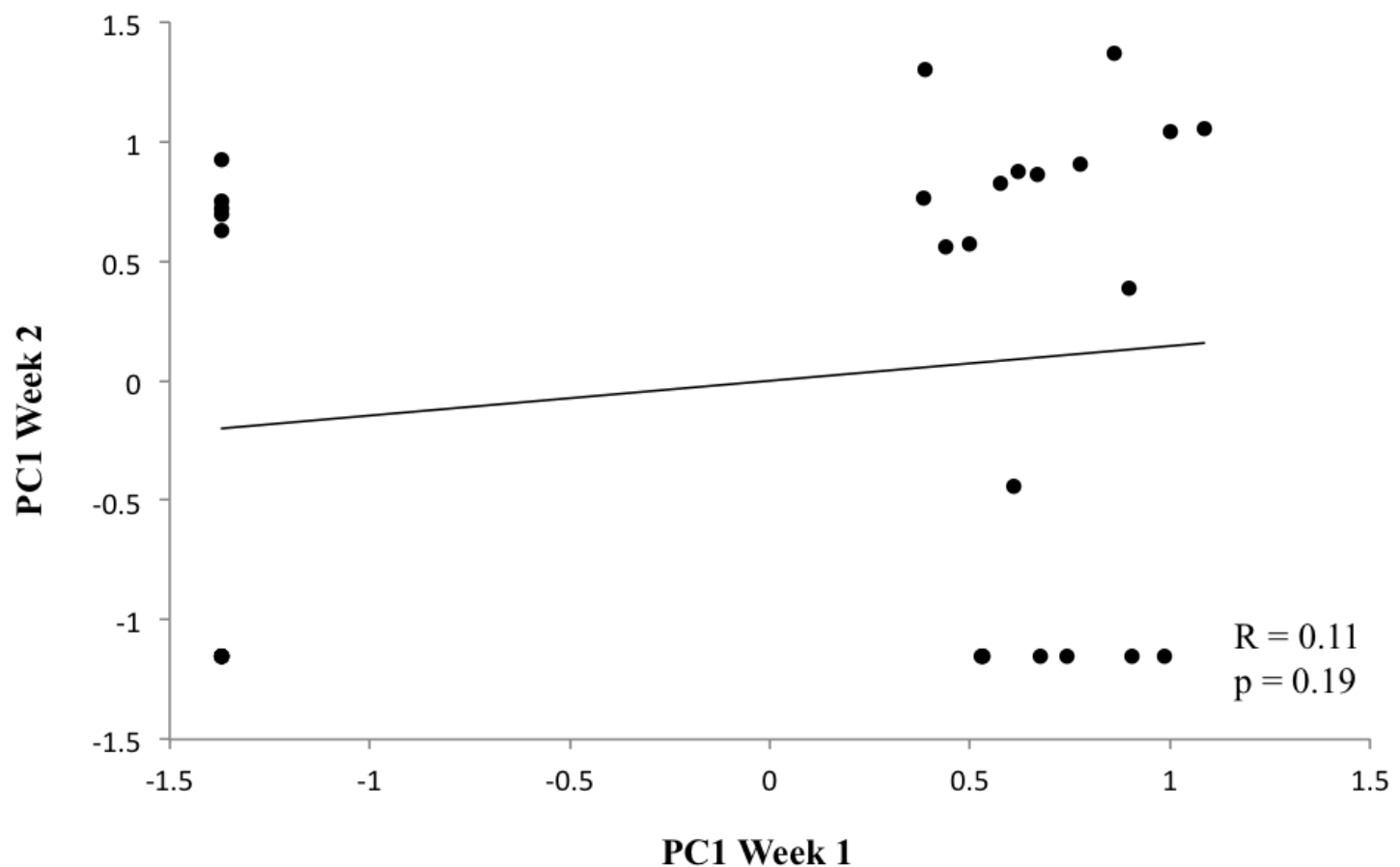

Figure 5. Repeatability (R) of PC1 scores for exploratory behaviour in the two repeated trials $(n=30)$. 
$(\mathrm{R}=0.17, \mathrm{SE}=0.19, \mathrm{CI}=0-0.61, \mathrm{p}=0.26)$.

Personality trait 2: Boldness under predation threat

A correlation matrix for the boldness behavioural measures (latency to exit the refuge, frequency of inspection bouts, total time spent inspecting, and median minimum distance approached to the predator model) revealed significant correlations between all four variables for both week 1 and week 2 (Table 2). Females who were quicker to exit the refuge (i.e. had a shorter latency time) spent more time inspecting the predator model, inspected the predator model for longer, and approached the predator model at a closer median distance than those who were slower to exit the refuge. These correlated variables were then collapsed into a single composite score (PC1) for boldness using PCA, with the first component accounting for approximately $87 \%$ of the total variance for week 1 and 81\% for week 2 (Appendix II - Table 2). Boldness, as measured by PC1 scores, was not repeatable from week 1 to week $2(\mathrm{R}=0.27, \mathrm{SE}=0.22, \mathrm{CI}=0-0.74, \mathrm{p}=0.17$; Fig. 6). The proportion of focal females exiting the refuge within 20 min in week 1 did not differ significantly from that in week $2\left(\mathrm{G}_{1}=0.28, \mathrm{p}>0.5\right)$. When analyzing only those females who did exit the refuge in both weeks 1 and 2, boldness was similarly not repeatable $(\mathrm{R}=0.02, \mathrm{SE}=0.22, \mathrm{CI}=0-0.69, \mathrm{p}=0.42)$.

\section{ii) Correlation between exploratory and boldness behaviours}

Female guppy exploratory behaviour in a novel environment and boldness under predation hazard were not significantly correlated for either week $1(\mathrm{r}=0.22, \mathrm{df}=28, \mathbf{p}=$ 0.23 ; Fig. 7a) or week $2(r=0.02, d f=28, p=0.89$; Fig. $7 b)$, suggesting that the exploratory tendency of individuals is independent of their boldness in the face of a 
Table 2. Correlation matrix using Pearson correlations (r) for measures of boldness for week 1 and week 2 . All variables were normalized by $\log _{10}$ transformation prior to analysis. The correlations shown in boldface are statistically significant $(* p<0.005, * * p$ $<0.0001)$.

\section{Week 1}

\begin{tabular}{|c|c|c|c|c|}
\hline & $\begin{array}{l}\text { Latency to exit } \\
\text { refuge }(\mathrm{s})\end{array}$ & $\begin{array}{l}\text { Frequency of } \\
\text { inspection } \\
\text { bouts }\end{array}$ & $\begin{array}{l}\text { Total time spent } \\
\text { inspecting (s) }\end{array}$ & $\begin{array}{l}\text { Minimum } \\
\text { distance } \\
\text { approached } \\
(\mathrm{cm})\end{array}$ \\
\hline $\begin{array}{l}\text { Latency to exit } \\
\text { refuge (s) }\end{array}$ & 1.00 & $-0.66 * *$ & $-0.64 * *$ & $-0.65 * *$ \\
\hline $\begin{array}{l}\text { Frequency of } \\
\text { inspection bouts }\end{array}$ & & 1.00 & $0.98 * *$ & $0.98 * *$ \\
\hline $\begin{array}{l}\text { Total time spent } \\
\text { inspecting }(\mathrm{s})\end{array}$ & & & 1.000 & $0.99 * *$ \\
\hline $\begin{array}{c}\text { Minimum } \\
\text { distance } \\
\text { approached }(\mathrm{cm})\end{array}$ & & & & 1.00 \\
\hline
\end{tabular}

\section{Week 2}

\begin{tabular}{|c|c|c|c|c|}
\hline & $\begin{array}{l}\text { Latency to exit } \\
\text { refuge (s) }\end{array}$ & $\begin{array}{l}\text { Frequency of } \\
\text { inspection } \\
\text { bouts }\end{array}$ & $\begin{array}{l}\text { Total time spent } \\
\text { inspecting (s) }\end{array}$ & $\begin{array}{l}\text { Minimum } \\
\text { distance } \\
\text { approached } \\
\text { (cm) }\end{array}$ \\
\hline $\begin{array}{l}\text { Latency to exit } \\
\text { refuge (s) }\end{array}$ & 1.000 & $-0.46^{*}$ & $-0.52 *$ & $-0.49 *$ \\
\hline $\begin{array}{l}\text { Frequency of } \\
\text { inspection bouts }\end{array}$ & & 1.00 & $0.98 * *$ & $0.91 * *$ \\
\hline $\begin{array}{l}\text { Total time spent } \\
\text { inspecting (s) }\end{array}$ & & & 1.00 & $0.95 * *$ \\
\hline $\begin{array}{c}\text { Minimum } \\
\text { distance } \\
\text { approached }(\mathrm{cm})\end{array}$ & & & & 1.00 \\
\hline
\end{tabular}




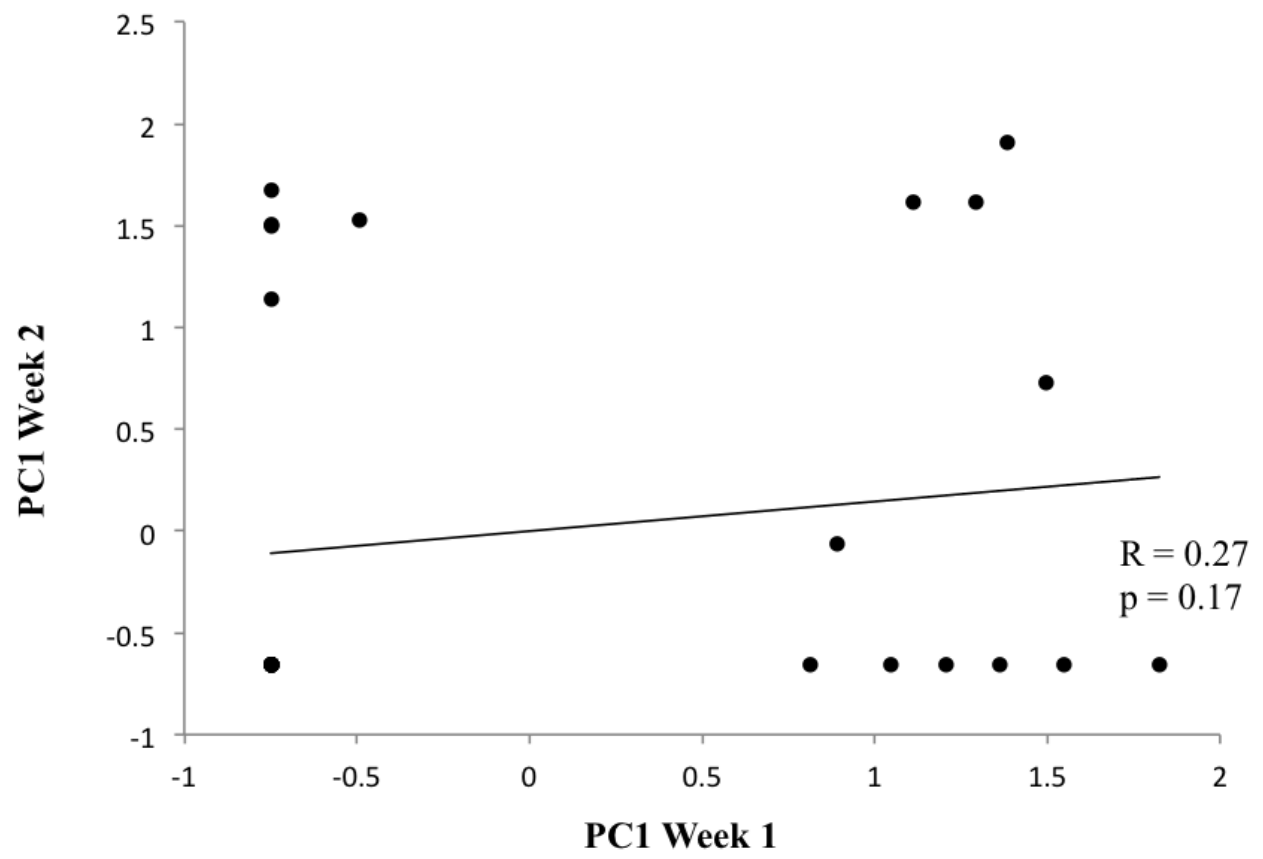

Figure 6. Repeatability (R) of PC1 scores for boldness in the two repeated trials $(n=30)$. 


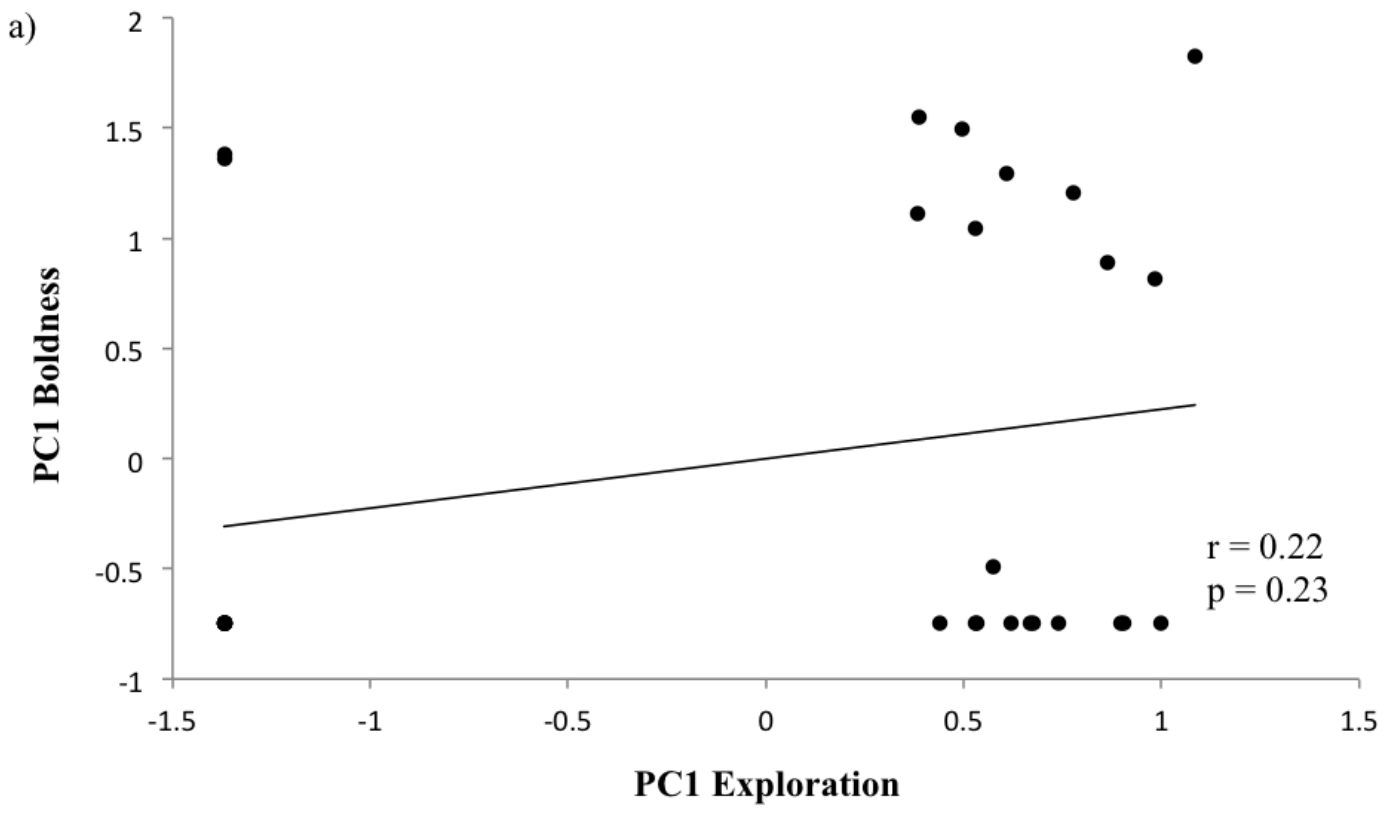

b)

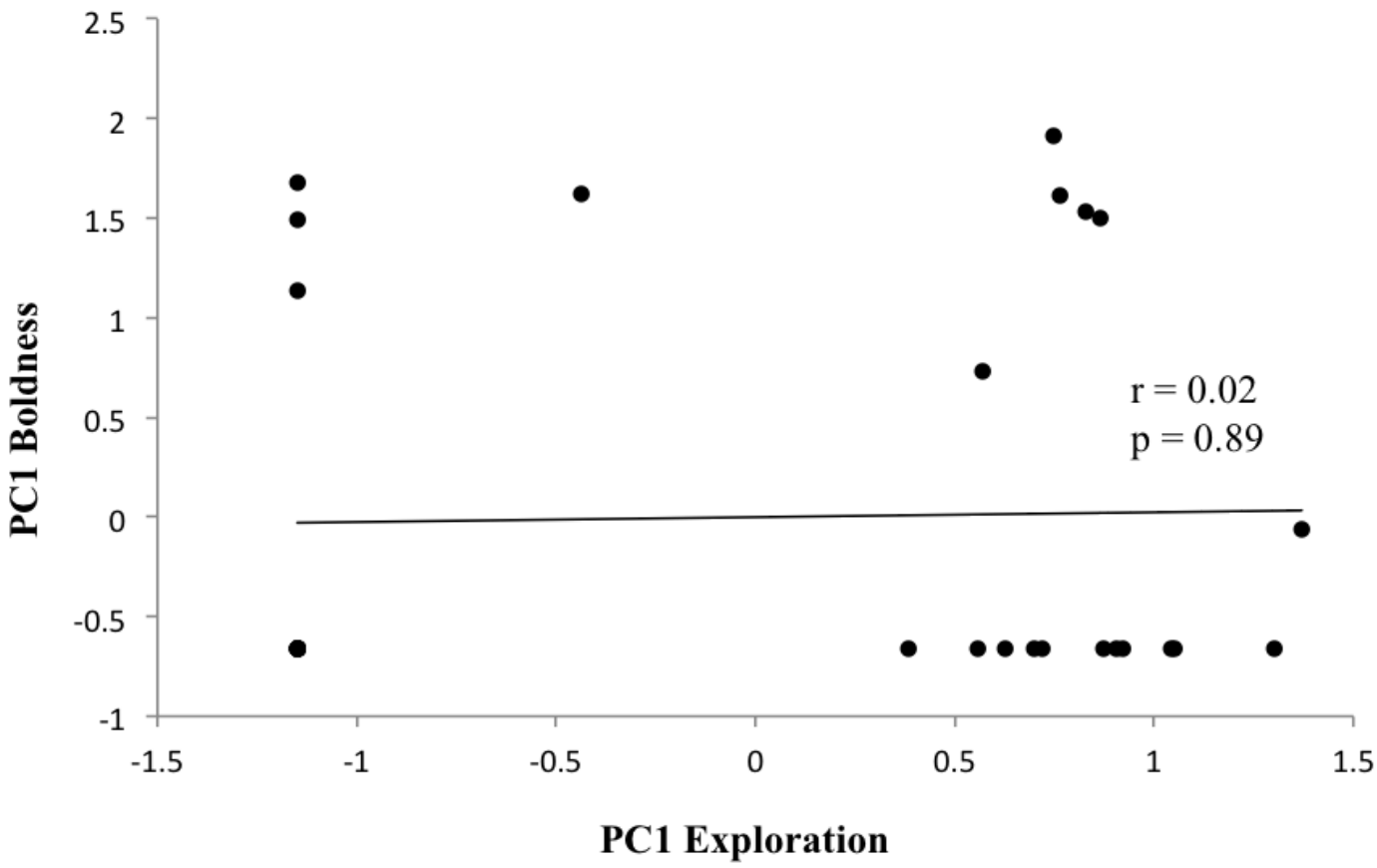

Figure 7. Pearson correlation (r) of PC1 scores for exploratory behaviour and boldness for week 1 (a) and week 2 (b). 
potential predation threat.

\section{Part B: Social information use and mate-choice copying behaviour i) Mate-choice copying tendency}

Focal females significantly reduced their time spent near the initially-preferred male after observing the initially non-preferred male sexually interacting with a model female compared with the control (independent $t$-test, $\mathrm{t}=-2.24, \mathrm{df}=40.2, \mathrm{p}=0.03$, twotailed; Fig. 8). This finding indicates that Upper Aripo females are able to mate-choice copy when given the opportunity to do so.

The body length of focal females and model females (Table 3) did not differ significantly from each other during week 1 (paired $t$-test, $\mathrm{t}=1.2, \mathrm{df}=24, \mathrm{p}=0.23$, two-tailed) and week 2 (paired $t$-test, $\mathrm{t}=1.5, \mathrm{df}=11, \mathrm{p}=0.14$ ). Similarly, the body length of paired stimulus males (Table 4) did not differ significantly from each other during week 1 (paired $t$-test, $\mathrm{t}=0.99, \mathrm{df}=24, \mathrm{p}=0.33$, two-tailed) and week 2 (paired t-test, $\mathrm{t}=-0.86$, $\mathrm{df}=11, \mathrm{p}=0.40)$. The body coloration pattern (Table 4$)$ of stimulus males did not differ significantly from each other during week 1 (paired t-test, $t=0.15, \mathrm{df}=24, \mathrm{p}=0.87$, two-tailed), or week 2 (paired t-test, $\mathrm{t}=-0.09, \mathrm{df}=11, \mathrm{p}=0.92$ ).

\section{ii) Repeatability of mate-choice copying}

Mate-choice copying tendency was not repeatable over time $(\mathrm{R}=-0.21, \mathrm{SE}=0.32$, $\mathrm{CI}=-0.97-0.53, \mathrm{p}=0.73 ;$ Fig. 9). However, only a small number of focal females $(\mathrm{n}=$ 9) had successful mate-choice copying trials (i.e. met all the criteria of mate choice described in the Methods section) in both week 1 and week 2. Consequently, statistical power here is low owing to this limited replicate sample size. 


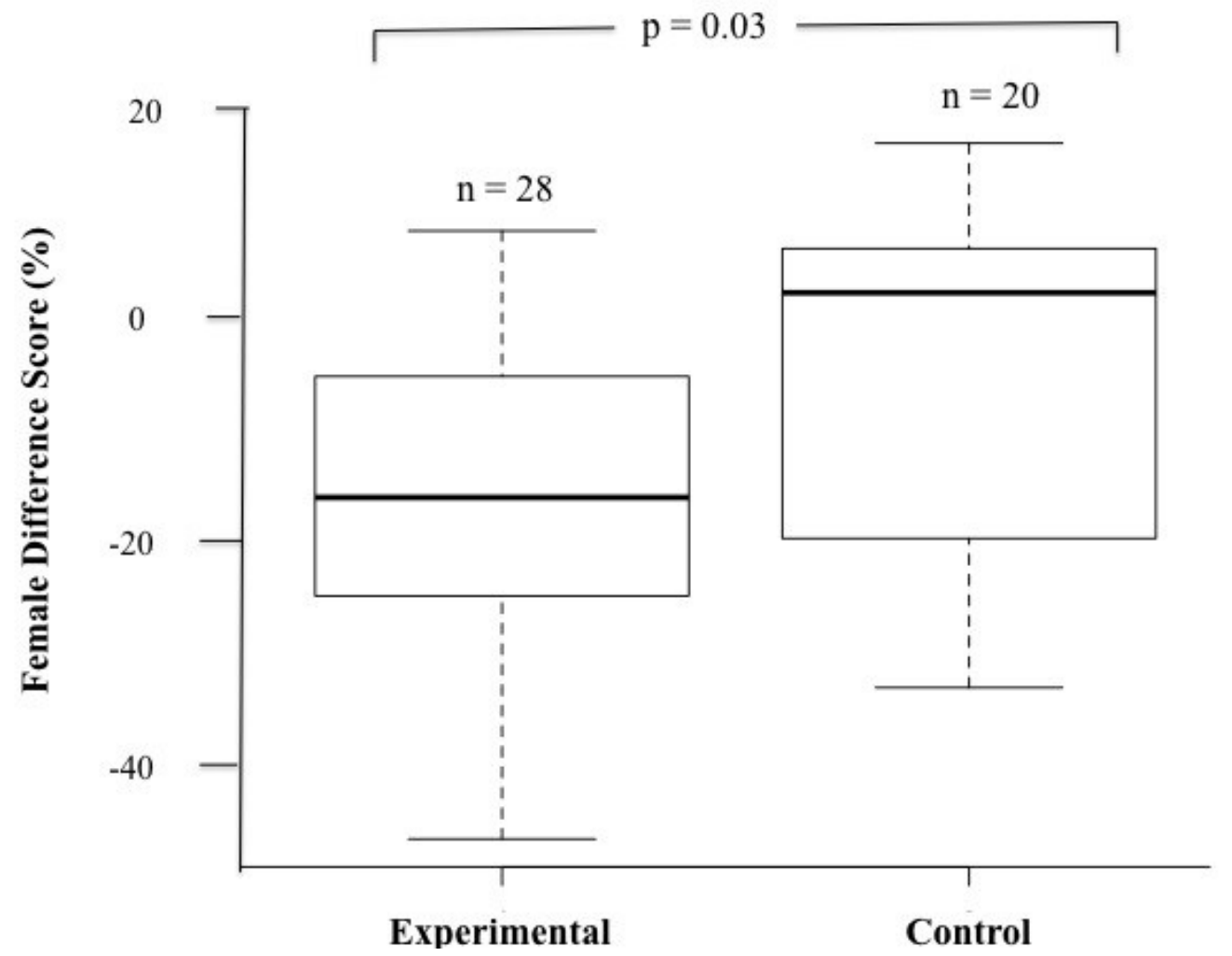

Figure 8. Female mating preference after viewing the preferred male in Phase 1 sexually interacting with a model female (Experimental) or in the absence of a model female (Control). A negative value indicates that focal females decreased their original preference in Phase 3. Box plots show the twenty-fifth, fiftieth (median) and seventy-fifth percentiles, with the whiskers indicating minimum and maximum values. 
Table 3. Standard body length ( $\mathrm{mm})$ for individual focal and model females used in trials in week 1 and week 2. Mean and standard error (SE) measures are shown below.

\begin{tabular}{|c|c|c|c|c|}
\hline & \multicolumn{2}{|c|}{ Week 1} & \multicolumn{2}{|c|}{ Week 2} \\
\hline & Focal & Model & Focal & Model \\
\hline \multirow[t]{25}{*}{ Body Length } & 21.5 & 21.0 & 23.8 & 23.0 \\
\hline & 22.1 & 20.0 & 24.1 & 23.5 \\
\hline & 22.7 & 22.0 & 24.1 & 23.5 \\
\hline & 22.0 & 22.0 & 23.5 & 25.0 \\
\hline & 21.5 & 22.0 & 27.5 & 26.0 \\
\hline & 24.0 & 25.0 & 24.8 & 25.0 \\
\hline & 24.1 & 23.0 & 23.2 & 22.0 \\
\hline & 24.1 & 23.0 & 21.7 & 22.0 \\
\hline & 20.7 & 22.0 & 23.2 & 22.0 \\
\hline & 24.7 & 25.0 & 22.1 & 21.0 \\
\hline & 23.5 & 25.0 & 22.0 & 23.0 \\
\hline & 22.9 & 22.0 & 24.9 & 24.0 \\
\hline & 22.1 & 23.0 & & \\
\hline & 21.8 & 23.0 & & \\
\hline & 27.5 & 26.0 & & \\
\hline & 23.2 & 23.0 & & \\
\hline & 24.8 & 25.0 & & \\
\hline & 25.7 & 26.0 & & \\
\hline & 23.2 & 22.0 & & \\
\hline & 23.2 & 23.0 & & \\
\hline & 23.5 & 22.0 & & \\
\hline & 22.1 & 22.0 & & \\
\hline & 22 & 22.0 & & \\
\hline & 23.4 & 23.0 & & \\
\hline & 24.9 & 24.0 & & \\
\hline Mean & 23.2 & 23.0 & 23.7 & 23.3 \\
\hline $\mathrm{SE}$ & 0.3 & 0.3 & 0.4 & 0.4 \\
\hline $\mathrm{n}$ & \multicolumn{2}{|c|}{25} & \multicolumn{2}{|c|}{12} \\
\hline
\end{tabular}


Table 4. Standard body length $(\mathrm{mm})$ and body coloration pattern (percent black and orange pigmentation on body) of paired stimulus males used in trials in week 1 and week 2. Mean and standard error (SE) measures are shown below.

\begin{tabular}{|c|c|c|c|c|}
\hline & \multicolumn{2}{|c|}{ Week 1} & \multicolumn{2}{|c|}{ Week 2} \\
\hline & Male 1 & Male 2 & Male 1 & Male 2 \\
\hline Body Length, & $18.3,0.14$ & $18.4,0.07$ & $15.8,0.05$ & $17.3,0.05$ \\
\hline Percent Colour & $18.7,0.04$ & $18.0,0.14$ & $16.1,0.13$ & $16.7,0.08$ \\
\hline & $18.8,0.12$ & $17.9,0.07$ & $15.7,0.05$ & $17.2,0.04$ \\
\hline & $18.6,0.07$ & $18.0,0.05$ & $18.4,0.09$ & $16.9,0.10$ \\
\hline & $18.4,0.08$ & $19.1,0.07$ & $17.7,0.21$ & $17.4,0.04$ \\
\hline & $16.4,0.12$ & $18.1,0.08$ & $17.2,0.08$ & $20.1,0.04$ \\
\hline & $17.2,0.06$ & $17.8,0.15$ & $17.3,0.10$ & $18.7,0.17$ \\
\hline & $15.1,0.04$ & $15.7,0.13$ & $17.1,0.08$ & $18.0,0.09$ \\
\hline & $16.0,0.06$ & $15.3,0.10$ & $19.9,0.07$ & $18.8,0.10$ \\
\hline & $15.6,0.05$ & $13.9,0.03$ & $15.8,0.08$ & $16.2,0.09$ \\
\hline & $17.4,0.12$ & $16.0,0.08$ & $20.1,0.09$ & $18.3,0.11$ \\
\hline & $17.0,0.14$ & $17.6,0.04$ & $18.2,0.07$ & $17.9,0.15$ \\
\hline & $17.8,0.12$ & $15.4,0.13$ & & \\
\hline & $16.2,0.10$ & $16.3,0.10$ & & \\
\hline & $19.6,0.07$ & $18.3,0.15$ & & \\
\hline & $17.2,0.04$ & $18.3,0.15$ & & \\
\hline & $16.7,0.07$ & $16.0,0.08$ & & \\
\hline & $18.2,0.07$ & $15.4,0.08$ & & \\
\hline & $17.0,0.09$ & $17.9,0.09$ & & \\
\hline & $15.7,0.08$ & $17.2,0.06$ & & \\
\hline & $18.4,0.21$ & $16.0,0.10$ & & \\
\hline & $15.6,0.07$ & $15.7,0.08$ & & \\
\hline & $16.3,0.08$ & $17.2,0.08$ & & \\
\hline & $15.6,0.10$ & $16.5,0.11$ & & \\
\hline & $18.3,0.08$ & $17.5,0.08$ & & \\
\hline Mean & $17.2,0.09$ & $16.9,0.09$ & $17.5,0.09$ & $17.8,0.09$ \\
\hline SE & $0.25,0.007$ & $0.25,0.006$ & $0.44,0.01$ & $0.31,0.01$ \\
\hline $\mathrm{n}$ & & & & \\
\hline
\end{tabular}




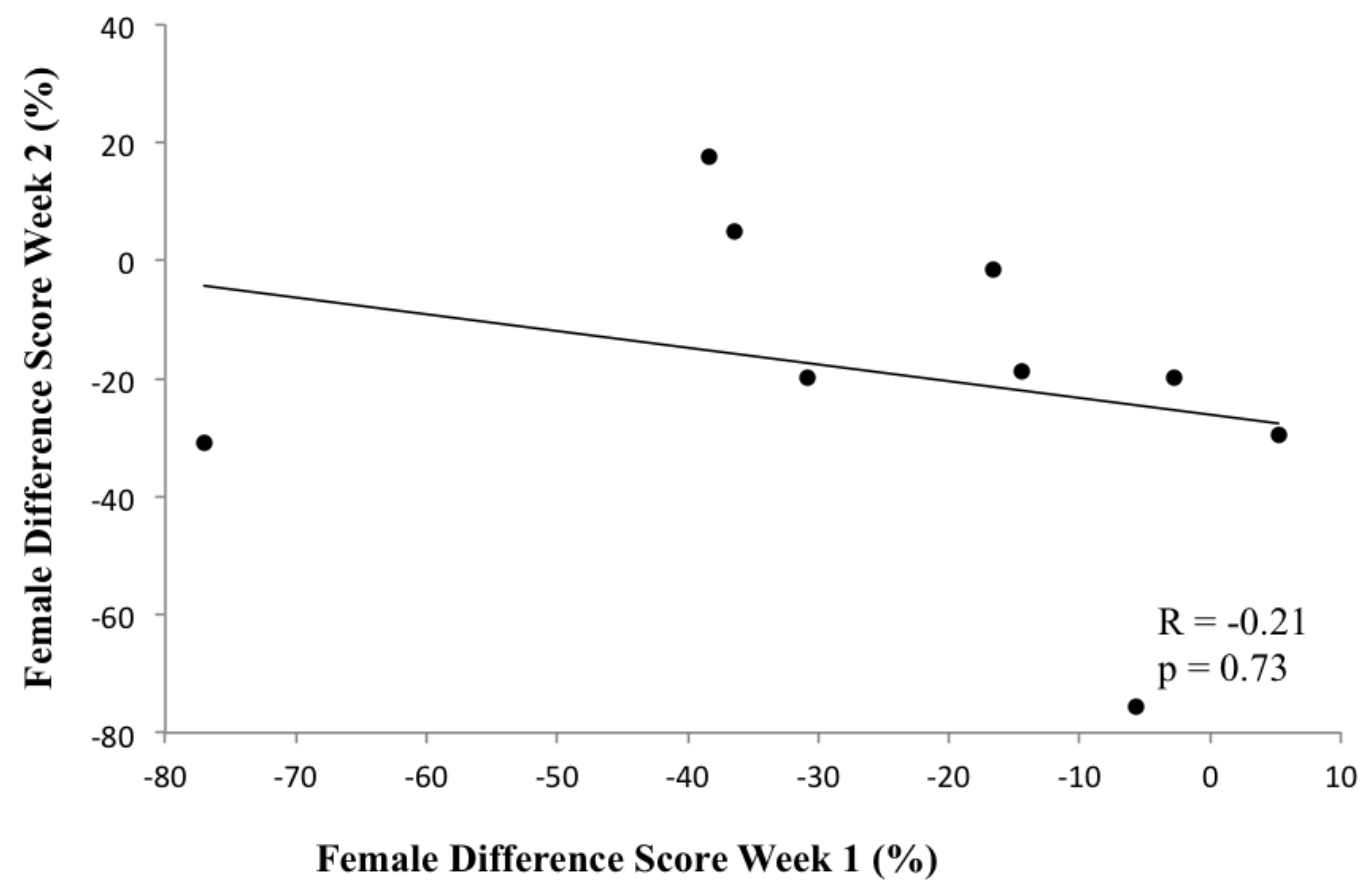

Figure 9. Repeatability (R) of mate-choice copying tendency as measured by difference scores (the proportion of time spent near the initially-preferred male in Phase 3 minus the proportion of time near the initially-preferred male in Phase 1) in the two repeated trials $(n=9)$. 


\section{Part C: Linking personality traits and mate-choice copying tendency}

To investigate correlations between measures of the two personality traits and mate-choice copying tendency for week 1, an additional correlation matrix was created for the four variables describing exploratory behaviour and a second one for the four measures describing boldness, since only focal females with successful mate-choice copying trials in week $1(n=25)$ were used in this analysis. As expected, all four variables of both exploratory behaviour and boldness were significantly inter-correlated (Table 5). Consequently, these correlated variables were collapsed into a single composite score (PC1) using PCA for exploration and boldness separately, with the first component accounting for approximately $81 \%$ of the total variance for exploratory behaviour and $84 \%$ for boldness (Appendix II - Table 3). The PC1 scores for exploratory behaviour and boldness were not correlated significantly with mate-choice copying difference scores for week 1 (Table 6). The above analysis was similarly carried out on the data for the repeated trials on week 2 (i.e., $n=12$ females that completed successful mate-choice copying trials). As for week 1, all four variables for both exploratory behaviour and boldness on week 2 were significantly inter-correlated (Table 7).

Consequently, these correlated variables were then collapsed into a single composite score (PC1) using PCA for exploration and boldness separately, with the first component accounting for approximately $89 \%$ of the total variance for exploratory behaviour, and 92\% for boldness (Appendix II - Table 4). The PC1 scores for exploratory behaviour and boldness were not correlated significantly with mate-choice copying difference scores for week 2 (Table 8). Importantly, for all PCA analyses, productmoment correlations revealed variable loadings that were highly correlated between week 1 and week 2 (Appendix II - Table 5). Neither the body length or personality traits of 
Table 5. Correlation matrix using Pearson correlations (r) for measures of exploratory behaviour and boldness for week 1 for females with successful mate-choice copying trials. All variables were normalized by $\log _{10}$ transformation prior to analysis. The correlations shown in boldface are statistically significant $(* p<0.05, * * p<0.005, * * * p<0.0001)$.

\begin{tabular}{|c|c|c|c|c|}
\hline \multicolumn{5}{|c|}{ Exploration } \\
\hline & $\begin{array}{l}\text { Latency to exit } \\
\text { refuge }(\mathrm{s})\end{array}$ & $\begin{array}{l}\text { Total distance } \\
\text { moved }(\mathrm{cm})\end{array}$ & $\begin{array}{c}\text { Time moving in } \\
\text { open zone }(\mathrm{s})\end{array}$ & $\begin{array}{l}\text { Time spent in } \\
\text { open zone }(\mathrm{s})\end{array}$ \\
\hline $\begin{array}{l}\text { Latency to exit } \\
\text { refuge }(\mathrm{s})\end{array}$ & 1.00 & $-0.42 *$ & $-0.42 *$ & $-0.42 *$ \\
\hline $\begin{array}{l}\text { Total distance } \\
\text { moved }(\mathrm{cm})\end{array}$ & & 1.00 & $0.99 * * *$ & $0.99 * * *$ \\
\hline $\begin{array}{l}\text { Time moving in } \\
\text { open zone (s) }\end{array}$ & & & 1.00 & $0.99 * * *$ \\
\hline $\begin{array}{l}\text { Time spent in } \\
\text { open zone (s) }\end{array}$ & & & & 1.00 \\
\hline \multicolumn{5}{|c|}{ Boldness } \\
\hline & $\begin{array}{l}\text { Latency to exit } \\
\text { refuge }(\mathrm{s})\end{array}$ & $\begin{array}{l}\text { Frequency of } \\
\text { inspection } \\
\text { bouts }\end{array}$ & $\begin{array}{c}\text { Total time } \\
\text { spent inspecting } \\
\text { (s) }\end{array}$ & $\begin{array}{l}\text { Minimum } \\
\text { distance } \\
\text { approached } \\
(\mathrm{cm})\end{array}$ \\
\hline $\begin{array}{l}\text { Latency to exit } \\
\text { refuge }(\mathrm{s})\end{array}$ & 1.00 & $-0.61 * *$ & $-0.54 * *$ & $-0.54 * *$ \\
\hline $\begin{array}{l}\text { Frequency of } \\
\text { inspection } \\
\text { bouts }\end{array}$ & & 1.00 & $0.98 * * *$ & $0.97 * * *$ \\
\hline $\begin{array}{l}\text { Total time spent } \\
\text { inspecting }(\mathrm{s})\end{array}$ & & & 1.00 & $0.98 * * *$ \\
\hline $\begin{array}{c}\text { Minimum } \\
\text { distance } \\
\text { approached }(\mathrm{cm})\end{array}$ & & & & 1.00 \\
\hline
\end{tabular}


Table 6. Correlation matrix using Pearson correlations (r) comparing PC1 scores for exploratory behaviour and boldness with difference scores as a measure of mate-choice tendency for focal females during week $1(n=25)$. No significant results are reported.

\begin{tabular}{cccc}
\hline & PC1 Exploration & PC1 Boldness & Difference score \\
\hline PC1 Exploration & 1.00 & 0.16 & 0.19 \\
PC1 Boldness & & 1.00 & 0.21 \\
Difference score & & 1.00 \\
\hline
\end{tabular}


Table 7. Correlation matrix using Pearson correlations (r) for measures of exploratory behaviour and boldness for week 2 for females with successful mate-choice copying trials. All variables were normalized by $\log _{10}$ transformation prior to analysis. The correlations shown in boldface are statistically significant $\left({ }^{*} \mathrm{p}<0.01,{ }^{* *} \mathrm{p}<0.001,{ }^{* * *} \mathrm{p}<0.0001\right)$.

\begin{tabular}{|c|c|c|c|c|}
\hline \multicolumn{5}{|c|}{ Exploration } \\
\hline & $\begin{array}{l}\text { Latency to exit } \\
\text { refuge }(\mathrm{s})\end{array}$ & $\begin{array}{c}\text { Total distance } \\
\text { moved }(\mathrm{cm})\end{array}$ & $\begin{array}{l}\text { Time moving in } \\
\text { open zone }(\mathrm{s})\end{array}$ & $\begin{array}{l}\text { Time spent in } \\
\text { open zone }(\mathrm{s})\end{array}$ \\
\hline $\begin{array}{l}\text { Latency to exit } \\
\text { refuge }(\mathrm{s})\end{array}$ & 1.00 & $-0.70 *$ & $-0.68 *$ & $-0.67 *$ \\
\hline $\begin{array}{l}\text { Total distance } \\
\text { moved }(\mathrm{cm})\end{array}$ & & 1.00 & $0.99 * * *$ & $0.99 * * *$ \\
\hline $\begin{array}{l}\text { Time moving in } \\
\text { open zone }(\mathrm{s})\end{array}$ & & & 1.00 & $0.99 * * *$ \\
\hline $\begin{array}{l}\text { Time spent in } \\
\text { open zone (s) }\end{array}$ & & & & 1.00 \\
\hline \multicolumn{5}{|c|}{ Boldness } \\
\hline & $\begin{array}{l}\text { Latency to exit } \\
\text { refuge }(\mathrm{s})\end{array}$ & $\begin{array}{l}\text { Frequency of } \\
\text { inspection } \\
\text { bouts }\end{array}$ & $\begin{array}{c}\text { Total time } \\
\text { spent } \\
\text { inspecting (s) }\end{array}$ & $\begin{array}{l}\text { Minimum } \\
\text { distance } \\
\text { approached } \\
(\mathrm{cm})\end{array}$ \\
\hline $\begin{array}{l}\text { Latency to exit } \\
\text { refuge }(\mathrm{s})\end{array}$ & 1.00 & $-0.79 * *$ & $-0.82 * * *$ & $-0.79 * *$ \\
\hline $\begin{array}{l}\text { Frequency of } \\
\text { inspection } \\
\text { bouts }\end{array}$ & & 1.00 & $0.99 * * *$ & $0.96 * * *$ \\
\hline $\begin{array}{l}\text { Total time spent } \\
\text { inspecting (s) }\end{array}$ & & & 1.00 & $0.98 * * *$ \\
\hline $\begin{array}{c}\text { Minimum } \\
\text { distance } \\
\text { approached }(\mathrm{cm})\end{array}$ & & & & 1.00 \\
\hline
\end{tabular}


Table 8. Correlation matrix using Pearson correlations (r) comparing PC1 scores for exploration and boldness with difference scores calculated during the mate-choice copying trial for focal females during week $2(n=12)$.

\begin{tabular}{cccc}
\hline & PC1 Exploration & PC1 Boldness & Difference score \\
\hline PC1 Exploration & 1.00 & -0.164 & 0.174 \\
PC1 Boldness & & 1.00 & -0.460 \\
Difference score & & 1.00 \\
\hline
\end{tabular}


focal females significantly influenced their mate-choice copying tendency, as a proxy of social information use, during either week $1(\mathrm{GLM}, \mathrm{F}=0.55, \mathrm{df}=3,21, \mathrm{p}=0.65)$ or week $2(\mathrm{~F}=2.4, \mathrm{df}=3,8, \mathrm{p}=0.14)$.

\section{DISCUSSION}

The current study attempted to answer the following questions. First, are two ecologically important personality traits, exploratory behaviour in a novel environment and boldness in the face of a simulated predation threat, repeatable in female guppies? Secondly, is the exploratory tendency of individuals in a novel environment correlated with their boldness in the face of a potential threat of predation, such that a behavioural syndrome exists? Third, is mate-choice copying behaviour repeatable? And, finally, are consistently more exploratory and bold females more or less likely to use social information and mate-choice copy when given the opportunity to do so?

My results revealed that, although all variables used to measure both exploratory behaviour and boldness were significantly inter-correlated, neither personality trait was significantly repeatable. With this being the case, it was to be expected that exploratory tendency would not correlate with boldness since no fixed personality traits were apparent, and consequently no behavioural syndrome was observed in this case. Female guppies from the Upper Aripo River were found to mate-choice copy when given the opportunity to do so, a phenomenon that had not been previously demonstrated for this population. However, mate-choice copying tendency was not found to be repeatable among individual females. Finally, mate-choice copying tendency in female guppies, and 
therefore the likelihood of using social information in a mating context, was not predicted by their personality (at least as characterized by their exploratory and boldness behaviours). The latter thus does not appear to be fixed in this population.

Consistent individual differences in behaviour have been reported in previous studies of the guppy. Budaev (1997) found Approach (active and sociable versus passive) and Fear Avoidance (bold versus fearful) to be two independent dimensions of personality in male guppies from a feral population of unknown origin. He concluded that these traits were consistent over time, but individual fish were tested on only three consecutive days. A more recent study by Biro (2012) on damselfish used rapid assays of behaviour, behavioural tests measured over a period of a few days (over a 7-day period in his study). He found that boldness, defined as a response to a simulated predation threat, was significantly repeatable, but that the responses of individuals within the first two days did not correlate with their responses later on days $3-7$. He found similar results for activity level, with significant patterns emerging only after day 2 . His results indicate that rapid assays of behavioural traits risk misclassifying individuals into particular behavioural types and can give an inaccurate assessment of personality.

In a study similar to Budaev, Burns (2008) ascertained the validity of three personality tests, one being the open-field test (similar to the test used in the current study for exploratory behaviour), using 12 wild populations of the Trinidadian guppy. Although he concluded that the open-field test is a good test of exploratory behaviour and that the reliabilities between populations did not differ from each other, a closer look at the within-population results for internal validity of the open-field tests revealed low correlations and non-significant values for many behavioural variables for the Upper Aripo River population. For his test-retest / short interval treatment, in which individual 
fish were tested in the same environment with 2 - 6 days between tests, only swimming rate and ratio of outer versus inner aquarium space explored were significant (with the latter having very low significance), while time spent immobile was found to be nonsignificant. For the alternate form/long interval treatment, in which two different apparatuses were used and tests were administered 14 weeks apart, none of the three behavioural variables were found to be repeatable. These results, taken together with the results of the current study, suggest that individual guppies originating from the Upper Aripo River population do not exhibit consistent individual differences in behaviour, with no fixed personality types emerging, and that their behaviours are rather flexible or plastic.

A plausible explanation for the lack of any observable fixed personality types, and therefore a lack of behavioural syndromes, is that this guppy population is exhibiting plasticity in behaviour. Behavioural plasticity is particularly important in species that inhabit heterogeneous environments with high amounts of environmental change, whether natural or human-disturbed (Sih et al., 2004a), because the development and expression of behaviour can be quite sensitive to changes in the ambient environment (Snell-Rood, 2013). In Trinidad, guppies live in a wide variety of environments, ranging from clear, nutrient-poor highland streams to more turbid, productive lowland streams to swamps (Houde, 1997). Streams and rivers inhabited by guppies frequently experience changes in water level and turbidity (droughts and floods) on different time scales (Houde, 1997). In the Upper Aripo River basin and many of the surrounding areas, there is heavy human disturbance and the water level and turbidity can rapidly rise over the course of a day (personal observations). These constantly changing conditions will tend to favour behavioural plasticity, as fixed behavioural types may not be appropriate in all 
situations (Moran, 1992). In the latter case, if individual fish were consistently exploratory or consistently bold (or vice versa), irrespective of ecological context, their behaviours could be maladaptive in the face of potential threats from predation and those caused by human activities (Schlaepfer et al., 2002).

A potential explanation for the lack of behavioural correlations (behavioural syndromes) in Upper Aripo female guppies is that this population has evolved under very low predation intensity. Comparisons of populations of three-spined sticklebacks have found that individuals from high-predation populations exhibit consistent behaviour towards predators and other conspecific competitors, whereas those from low-predation populations do not (Bell, 2005). In a follow-up experiment by Bell and Sih (2007), a lowpredation population of sticklebacks was tested for their boldness and aggressiveness both before and after the experimental exposure of the sticklebacks to trout (Oncorhynchus mykiss) predation (i.e. after half the fish had been consumed). While stickleback aggressiveness was not correlated with their boldness prior to predation, these two behavioural traits were significantly correlated afterwards and thus a predatorinduced behavioural syndrome emerged. The researchers found that both behavioural variability and selection by predators contributed to the formation of a behavioural syndrome: individual sticklebacks altered their behaviour in response to trout predation, and selection favoured those who were more aggressive and less bold as bolder, less aggressive individuals were more likely to be consumed. The conclusion from these studies on sticklebacks is that some behavioural correlations may be favoured in certain environments, but not in others. In light of the latter findings, it is conceivable that low predation intensity on guppies in the Upper Aripo River did not favour the evolution of 
consistent differences in behaviour nor correlations between particular behaviours (i.e. behavioural syndromes).

In the current study, female guppies were observed to copy the mate-choice of other nearby females when given the opportunity to do so. This is consistent with the behaviour of female guppies from other populations in Trinidad, including the Turure River (Dugatkin, 1992; Dugatkin and Godin, 1992c), Paria River (Dugatkin and Godin, 1998; Dugatkin et al., 2002, 2003; Godin et al., 2005) and Quaré River (Briggs et al., 1996; Godin and Hair, 2009) populations. However, in the current study, the mate-choice copying tendency of individual virgin female guppies was not consistent and repeatable. Because of my rigorous conservative criteria that had to be met for a mate-choice copying trial to be deemed successful in the current study and because of illness that resulted in six females dying before being re-tested a week later, only nine females had successful trials for both week 1 and 2; this small replicate sample size limited the power of the test for repeatability of behaviour. Brooks (1996) found that although female choice was repeatable in the absence of a copying opportunity, mate-choice copying was not repeatable when the same stimulus males were used between repeated trials. He concluded that repeatability was reduced since the female's original mate choice decision was contradicted in the repeated choice test. He argued that the opposite would probably occur in the wild, since observing other females mating with a preferred male is likely to make the preference stronger rather than weaker. In this study, it was not the repeatability of preference for a particular male that was of interest, but rather the repeatability of mate-choice copying tendency per se, and whether a female is likely to consistently use social rather than personal information in making mating decisions. 
Sample size is one of the major factors in determining statistical power, which measures the probability that a true difference in the data will be detected by a study (Taborsky, 2010). In other words, it is the sample size of a study that determines the probability of rejecting a null hypothesis of no difference when no difference truly exists. A study by Taborsky (2010) examined sample sizes of 119 studies taken from a mix of five different animal behaviour journals from 2009. When comparing observational and experimental studies, he found that average sample sizes were significantly less for experimental studies ( $\mathrm{n}=34$ and 20.9, respectively). Similarly, when comparing field studies with those performed in a captive setting, average sample sizes were significantly less for those in a captive setting ( $\mathrm{n}=32$ and 18 , respectively). The main conclusions drawn from this study are that it is common to have relatively low sample sizes when studies are experimental compared with observational, are taking place in a captive (i.e. laboratory) setting, and when they involve vertebrates. However, these restrictions tend to be due to the availability of test subjects, and ethical reasons such as wanting to avoid housing or disturbing large numbers of animal participants. Although relatively small sample sizes are considered to be acceptable (Taborsky, 2010), in the case of the current study, a sample size of 9 is too small to be able to confidently conclude that mate-choice copying tendency in Upper Aripo female guppies is not repeatable.

Although the current study is not the first to investigate personality and behavioural syndromes in the guppy, it is the first to my knowledge to have used virgin females from the Upper Aripo River, a low-predation population, as study subjects. It would appear that female guppies from this population are flexible in their behaviour, and consequently do not exhibit suites of correlated repeatable behaviours or behavioural syndromes, perhaps as an adaptive response to highly heterogeneous and unpredictable 
riverine environments and (or) to weak predation pressure. Future manipulative and comparative research should be carried out to ascertain whether predation intensity is associated with the emergence and maintenance of behavioural syndromes in Upper Aripo river guppies, as has been done for the three-spined stickleback (Bell, 2005; Bell and Sih, 2007).

The current study also appears to be the first to investigate a potential link between ecologically important personality traits (exploration and boldness or risk taking) and mate-choice copying tendency as a measure of social information use. Since exploratory behaviour was not correlated with boldness, and because neither personality trait was found to be repeatable, it was to be expected that no correlations were observed with an individual's tendency to mate-choice copy. Because of a low sample size, due in part to illness in some of the focal females and the conservative criteria required for a successful mate-choice copying trial, I cannot yet rule out the alternative outcome that mate-choice copying tendency is repeatable in Upper Aripo River female guppies. 


\section{REFERENCES}

Adriaenssens, B., and Johnsson, J.I. 2012. Natural selection, plasticity and the emergence of a behavioural syndrome in the wild. Ecology Letters, 16: 47 - 55 .

Bell, A.M. 2005. Differences between individuals and populations of threespined stickleback. Journal of Evolutionary Biology, 18: 464 - 473.

Bell, A.M., Hankinson, S.J., and Laskowski, K.L. 2009. The repeatability of behaviour: a meta-analysis. Animal Behaviour, 77: 771-783.

Bell, A.M., and Sih, A. 2007. Exposure to predation generates personality in threespined sticklebacks (Gasterosteus aculeatus). Ecology Letters, 10: 828 - 834.

Biro, P.A. 2012. Do rapid assays predict reliability in labile (behavioural) traits? Animal Behaviour, 83: $1295-1300$.

Blumstein, D.T., and Daniel, J.C. 2007. Quantifying behavior the JWatcher way. Sinauer Associates Inc., Sunderland, MA.

Boon, A.K., Réale, D., and Boutin, S. 2007. The interaction between personality, offspring fitness and food abundance in North American red squirrels. Ecology Letters, 10: $1094-1104$.

Briggs, S.E., Godin, J.-G.J, and Dugatkin, L.A. 1996. Mate-choice copying under predation risk in the Trinidadian guppy (Poecilia reticulata). Behavioral Ecology, 7: 151-157.

Brooks, R. 1996. Copying and the repeatability of mate choice. Behavioral Ecology and Sociobiology, 39: 323-329.

Brown, C., and Laland, K. 2001. Social learning and life skills training for hatchery reared fish. Journal of Fish Biology, 59: 471-493. 
Brown, C., and Laland, K. 2003. Social learning in fishes: a review. Fish and Fisheries, 4: 280-288.

Budaev, S.V. 1997. "Personality" in the guppy (Poecilia reticulata): a correlational study of exploratory behavior and social tendency. Journal of Comparative Psychology, 111: 399-411.

Budaev, S.V., Zworykin, D.D., and Mocheck, A.D. 1999. Individual-differences in parental care and behavioural profile in the convict cichlid: A correlational study. Animal Behaviour, 58: 195 - 202.

Burns, J.G. 2008. The validity of three tests of temperament in guppies (Poecilia reticulata). Journal of Comparative Psychology, 122: 344-356.

Carter, A.J., Feeney, W.E., Marshall, H.H., Cowlishaw, G., and Heinsohn, R. 2013. Animal personality: what are behavioural ecologists measuring? Biological Reviews, 88: $465-475$.

Coleman, K., and Wilson, D.S. 1998. Shyness and boldness in pumpkinseed sunfish: individual differences are context-specific. Animal Behaviour, 56: 927 - 936.

Conrad, J.L., Weinersmith, K.L., Brodin, T., Saltz, J.B., and Sih, A. 2011. Behavioural syndromes in fishes: a review with implications for ecology and fisheries management. Journal of Fish Biology, 78: 395 - 435.

Coolen, I., Dangles, S., and Casas, J. 2005. Social learning in non-colonial insects? Current Biology, 15: 1931-1935.

Dall, S.R.X., Giraldeau, L.-A., Olsson, O., McNamara, J.M., and Stephens, D.W. 2005. Information and its use by animals in evolutionary ecology. Trends in Ecology and Evolution, 20: 187 - 193. 
Danchin, E., Giraldeau, L.-A., Valone, T.J., and Wagner, R.H. 2004. Public information: from nosy neighbors to cultural evolution. Science, 305: 486-491.

DeWitt, T.J., Sih, A., and Wilson, D.S. 1998. Costs and limits of phenotypic plasticity. Trends in Ecology and Evolution, 13: 77 - 81.

Dingemanse, N.J., Both, C., van Noordwijk, A.J., Rutten, A.L., and Drent, P.J. 2003. Natal dispersal and personalities in great tits (Parus major). Proceedings of the Royal Society of London B - Biological Sciences, 270: 741 - 747.

Dingemanse, N.J., and Réale, D. 2005. Natural selection and animal personality. Behaviour, 142: 1159-1184.

Dixon, W.J. 1950. Analysis of extreme values. The Annals of Mathematical Statistics, 21: $488-506$.

Dosen, L.D., and Montgomerie, R. 2004. Female size influences mate preference of male guppies. Ethology, 110: 244-255.

Dugatkin, L.A. 1992. Sexual selection and imitation: females copy the mate choice of others. American Naturalist, 139: 1384-1389.

Dugatkin, L.A. 1996. Interface between culturally based preferences and genetic preferences: Female mate choice in Poecilia reticulata. Proceedings of the National Academy of Sciences USA, 93: 2770-2773.

Dugatkin, L.A., and Godin, J.-G.J. 1992a. Predator inspection, shoaling and foraging under predation hazard in the Trinidadian guppy, Poecilia reticulata. Environmental Biology of Fishes, 34: 265-276.

Dugatkin, L.A., and Godin, J.-G.J. 1992b. Prey approaching predators: a cost-benefit perspective. Annales Zoologici Fennica, 29: 233-252. 
Dugatkin, L.A., and Godin, J.-G.J. 1992c. Reversal of female mate choice by copying in the guppy (Poecilia reticulata). Proceedings of the Royal Society of London BBiological Sciences, 249: 179-184.

Dugatkin, L.A., and Godin, J.-G.J. 1993. Female mate copying in the guppy (Poecilia reticulata): age-dependent effects. Behavioral Ecology, 4: 289 - 292.

Dugatkin, L.A., and Godin, J.-G.J. 1998. Effects of hunger on mate-choice copying in the guppy. Ethology, 104: $194-202$.

Dugatkin, L.A., Lucas, J.S., and Godin, J.-G.J. 2002. Serial effects of mate-choice copying in the guppy (Poecilia reticulata). Ethology, Ecology and Evolution, 14: $45-52$.

Dugatkin, L.A., Druen, M.W., and Godin, J.-G.J. 2003. The disruption hypothesis does not explain mate-choice copying in the guppy (Poecilia reticulata). Ethology, 109:67-76.

Eysenck, H.J., and Eysenck, M.W.1985. Personality and individual differences: A natural science approach. New York: Plenum Press.

Foster, S.A., and Sih, A. 2013. Behavioural plasticity and evolution. Animal Behaviour, 85: 1003.

Francis, R. 1990. Temperament in a fish: A longitudinal study of the development of individual differences in aggression and social rank in the Midas cichlid. Ethology, 86: 311-325.

Galef, B.G. 2009. Strategies for social learning: Testing predictions from formal theory. Advances in the Study of Behavior, 39: 117 - 151.

Galef, B.G., and White, D.J. 1998. Mate-choice copying in Japanese quail, Coturnix coturnix japonica. Animal Behaviour, 55: 545 - 552. 
Galef, B.G., and White, D.J. 2000. Evidence of social effects on mate choice in vertebrates. Behavioural Processes, 51: $167-175$.

Garcia-Sevilla, L.1984. Extraversion and neuroticism in rats. Personality and Individual Differences, 5: 511-532.

Gibson, R.M., and Höglund, J. 1989. Copying and sexual selection. Trends in Ecology and Evolution, 7: $229-232$.

Giraldeau, L.-A., Valone, T.J., and Templeton, J.J. 2002. Potential disadvantages of using socially acquired information. Philosophical Transactions of the Royal Society B, 357: $1559-1566$.

Godin, J.-G.J. 1997. Evading predators. In: Behavioural Ecology of Teleost Fishes, edited by J.-G.J. Godin. Oxford University Press, Oxford. Pp. 191 - 236.

Godin, J.-G.J. 2010. Fish social learning. Encyclopedia of Animal Behavior, 1: 725729.

Godin, J.-G.J., and Davis, S.A.1995. Who dares, benefits: predator approach behaviour in the guppy (Poecilia reticulata) deters predator pursuit. Proceedings of the Royal Society of London B - Biological Sciences, 259: 193-200.

Godin, J.-G.J., and Dugatkin, L.A. 1995. Variability and repeatability of female mating preference in the guppy. Animal Behaviour, 49: 1427-1433.

Godin, J.-G.J., and Dugatkin, L.A. 1996. Female mating preference for bold males in the guppy, Poecilia reticulata. Proceedings of the National Academy of Sciences USA, 93: $10262-10267$.

Godin, J.-G.J., and Hair, K.P.E. 2009. Mate-choice copying in free-ranging Trinidadian guppies (Poecilia reticulata). Behaviour, 146: 1443-1461. 
Godin, J.-G.J., Herdman, E.J.E., and Dugatkin, L.A. 2005. Social influences on female mate choice in the guppy, Poecilia reticulata: generalized and repeatable traitcopying behaviour. Animal Behaviour, 69: 999-1005.

Grant, J.W., and Green, L.D. 1996. Mate copying versus preferences for actively courting males by female Japanese medaka (Oryzias latipes). Behavioral Ecology, 7: 165 $-167$.

Grocott, D.F.H. 2003. Maps in mind - how animals get home? The Journal of Navigation, 56: $1-14$.

Harcourt, J.L., Biau, S., Johnstone, R., and Manica, A. 2010. Boldness and information use in three-spined sticklebacks. Ethology, 116: 440 - 447.

Heyes, C.M. 1994. Social learning in animals: Categories and mechanisms. Biological Reviews, 69: $207-231$.

Houde, A.E. 1997. Sex, color, and mate choice in guppies. Princeton University Press, Princeton.

Hughes, K.L., Du, L., Rodd, F.H., and Reznick, D.N. 1999. Familiarity leads to female mate preference for novel males in the guppy, Poecilia reticulata. Animal Behaviour, 58: 907-916.

Jeswiet, S.B., and Godin, J.-G.J. 2011. Validation of a method for quantifying male mating prefrences in the guppy (Poecilia reticulata). Ethology, 117: 422-429.

Jeswiet, S.B., Lee-Jenkins, S.S.Y., Ramnarine, I.W., and Godin, J.-G.J. 2011. Sperm competition risk and mate choice in male Trinidadian guppies, Poecilia reticulata. Animal Behaviour, 81: 639-644. 
Johanessen, L.E., Slagsvold, T., and Hansen, B.T. 2006. Effects of social rearing conditions on song structure and repertoire size: Experimental evidence from the field. Animal Behaviour, 72: 83-95.

Johnson, J.C., and Sih, A. 2005. Pre-copulatory sexual cannibalism in fishing spiders (Dolomedes triton): a role for behavioral syndromes. Behavioral Ecology and Sociobiology, 58: $390-396$.

Jones, K.A., and Godin, J.-G.J. 2010. Are fast explorers slow reactors? Linking personality type and anti-predator behaviour. Proceedings of the Royal Society $B$, 277: 625-632.

Kendal, R.L., Coolen, I., Bergen, Y.V., and Laland, K. 2005. Trade-offs in the adaptive use of social and asocial learning. Advances in the Study of Behavior, 35: 333 379.

Krause, J., and Ruxton, G.D. 2002. Living in groups. Oxford University Press, Oxford.

Kodric-Brown, A., and Nicoletto, P.F. 1997. Repeatability of female choice in the guppy: response to live and videotaped males. Animal Behaviour, 54: 369-376.

Kubinyi, E., Pongracz, P., and Miklosi, A. 2009. Dog as a model for studying conspecific and heterospecific social learning. Journal of Veterinary Behavior, 4: 31-41.

Kurvers, R.H.J.M., van Oers, K., Nolet, B.A., Jonker, R.M., van Wieren, S.E., Prins, H.H.T., and Ydenberg, R.C. 2010. Personality predicts the use of social information. Ecology Letters, 13: 829 - 837.

Magurran, A.E., 2005. Evolutionary ecology: the Trinidadian guppy. Oxford University Press, Oxford.

Magurran, A.E., and Girling, S.L. 1986. Predator model recognition and response habituation in shoaling minnows. Animal Behaviour, 34: $510-518$. 
Marchetti, C., and Drent, P.J. 2000. Individual differences in the use of social information in foraging by captive great tits. Animal Behaviour, 60: $131-140$.

Moran, N.A. 1992. The evolutionary maintenance of alternative phenotypes. American Naturalist, 139: 971 - 989.

Nakagawa, S., and Schielzeth, H. 2010. Repeatability for Gaussian and non-Gaussian data: a practical guide for biologists. Biological Reviews, 85: 935 - 956.

Nomakuchi, S., Park, P.J., and Bell. M.A. 2009. Correlation between exploration activity and use of social information in three-spined sticklebacks. Behavioral Ecology, 20: $340-345$.

Pruett-Jones, S. 1992. Independent versus nonindependent mate choice: Do females copy each other? American Naturalist, 140: 1000-1009.

Réale, D., Reader, S.M., Sol, D., McDougall, P.T., and Dingemanse, N.J. 2007. Integrating animal temperament within ecology and evolution. Biological Reviews, 82: 291-318.

Reynolds, J.D., and Jones, J.C. 1999. Female preference for preferred males is reversed under low oxygen conditions in the common goby (Pomatoschistus microps). Behavioral Ecology, 10: 149 - 154.

Schlaepfer, M.A., Runge, M.C., and Sherman, P.W. 2002. Ecological and evolutionary traps. Trends in Ecology and Evolution, 17: $474-480$.

Schlupp, I., Marler, C., and Ryan, M.J. 1994. Benefit to male sailfin mollies of mating with heterospecific females. Science, 263: 373-374.

Schlupp I., and Ryan M.J. 1997. Male sailfin mollies (Poecilia latipinna) copy the mate choice of other males. Behavioral Ecology, 8: 104-107. 
Schuett, W., Godin, J.-G.J., and Dall, S.R.X. 2011. Do female zebra finches, Taeniopygia guttata, choose their mates based on their 'personality'? Ethology, 117: 908-917.

Sih, A., and Bell, A.M. 2008. Insights for behavioral ecology from behavioral syndromes. Advances in the Study of Behavior, 38: 227-281.

Sih, A., Bell, A.M., Johnson, J.C., and Ziemba, R.E. 2004a. Behavioral syndromes: an ecological and evolutionary overview. Trends in Ecology and Evolution, 19: $372-378$

Sih, A., Bell, A.M., Johnson, J.C., and Ziemba, R.E. 2004b. Behavioral syndromes: an integrative overview. Quarterly Review of Biology, 79: 241-277.

Snell-Rood, E.C. 2013. An overview of the evolutionary causes and consequences of behavioural plasticity. Animal Behaviour, 85: $1004-1011$.

Taborsky, M. 2010. Sample size in the study of behaviour. Ethology, 116: $185-202$.

Toms, C.N., Echevarria, D.J., and Jouandot, D.J. 2010. A methodological review of personality-related studies in fish: focus on the shy-bold axis of behaviour. International Journal of Comparative Psychology, 23: 1-25.

van Oers, K., Klunder, M., and Drent, P.J. 2005. Context dependence of personalities: risk-taking behavior in a social and non-social situation. Behavioral Ecology, 16: $716-723$

Webster, M.M., and Ward, A.J.W. 2010. Personality and social context. Biological Reviews, 86: 759-773.

Webster, M.M., Ward, A.J.W., and Hart, P.J.B. 2009. Individual boldness affects interspecific interactions in sticklebacks. Behavioral Ecology and Sociobiology, 63: $511-520$. 
Westneat, D.F., Walters, A., McCarthy, T.M., Hatch, M.I., and Hein, W.K. 2000. Alternative mechanisms of nonindependent mate choice. Animal Behaviour, 59: 467-476.

Wilson, A.D.M., and Godin, J.-G.J. 2009. Boldness and behavioral syndromes in the bluegill sunfish, Lepomis macrochirus. Behavioral Ecology, 20: 231-237.

Witte, K., and Massmann, R. 2003. Female sailfin mollies, Poecilia latipinna, remember males and copy the choice of others after 1 day. Animal Behaviour, 65: $1151-$ 1159. 


\section{APPENDIX I}

\section{Ethovision Software Validation}

In order to ensure Ethovision XT video-analysis system (Noldus Information Technology, Leesburg, VA) was an accurate way to measure behaviour, a 300-second sample of each exploratory behaviour trial in which the focal female exited the refuge was analyzed. Time spent in the open zone and time spent swimming while in the open zone were calculated both manually (using a stopwatch) and using Ethovision software (Table 1). Pearson correlations for time spent in the open zone when measured manually compared with Ethovision software were found to be highly correlated for both week 1 (r $=0.99, \mathrm{df}=22, \mathrm{p}<0.000, \mathrm{n}=24)$, and week $2(\mathrm{r}=0.99, \mathrm{df}=16, \mathrm{p}<0.000, \mathrm{n}=18)$. Pearson correlations for time spent moving while in the open zone when measured manually compared with Ethovision software were found to be highly correlated for both week $1(\mathrm{r}=0.96, \mathrm{df}=22, \mathrm{p}<0.000, \mathrm{n}=24)$, and week $2(\mathrm{r}=0.99, \mathrm{df}=16, \mathrm{p}<0.000, \mathrm{n}$ $=18$ ). These results indicate that Ethovision software is a reliable way to measure behaviour. 
Table 1. Measures of time spent in the open zone (s) and time spent moving while in the open zone (s) when recording manually using a stopwatch, compared with Ethovision XT video-analysis system. Each measure is based on a 300 -second sample of each video clip in which the female exited the refuge.

\begin{tabular}{cccccccc}
\hline \multicolumn{2}{c}{ Week 1 } & \multicolumn{5}{c}{ Week 2 } \\
\hline \multicolumn{2}{c}{ Manual } & \multicolumn{2}{c}{ Ethovision } & \multicolumn{2}{c}{ Manual } & \multicolumn{2}{c}{ Ethovision } \\
\hline Time in & Time & Time in & Time & Time in & Time & Time in & Time \\
the open & spent & the open & spent & the open & spent & the open & spent \\
zone & moving & zone & moving & zone & moving & zone & moving \\
\hline 268 & 265 & 268 & 250 & 228 & 208 & 228 & 190 \\
300 & 281 & 300 & 272 & 300 & 266 & 300 & 264 \\
248 & 233 & 248 & 210 & 97 & 92 & 96 & 90 \\
192 & 173 & 190 & 175 & 2 & 2 & 1 & 1 \\
300 & 286 & 300 & 254 & 125 & 92 & 123 & 90 \\
300 & 147 & 300 & 139 & 236 & 221 & 235 & 209 \\
128 & 109 & 127 & 119 & 105 & 76 & 104 & 72 \\
268 & 256 & 267 & 262 & 300 & 246 & 300 & 240 \\
177 & 142 & 175 & 142 & 300 & 271 & 300 & 260 \\
300 & 289 & 300 & 285 & 156 & 143 & 155 & 141 \\
160 & 137 & 158 & 128 & 300 & 269 & 300 & 274 \\
300 & 265 & 300 & 214 & 143 & 135 & 140 & 137 \\
300 & 255 & 300 & 204 & 206 & 195 & 204 & 188 \\
300 & 221 & 300 & 239 & 219 & 124 & 217 & 115 \\
300 & 274 & 300 & 265 & 24 & 19 & 22 & 17 \\
194 & 183 & 194 & 187 & 300 & 268 & 300 & 277 \\
169 & 148 & 170 & 151 & 300 & 280 & 300 & 258 \\
179 & 150 & 180 & 139 & 277 & 233 & 277 & 216 \\
251 & 235 & 253 & 239 & & & & \\
245 & 209 & 245 & 201 & & & & \\
208 & 182 & 207 & 178 & & & & \\
300 & 234 & 300 & 250 & & & & \\
50 & 37 & 49 & 35 & & & & \\
282 & 228 & 280 & 235 & & & & \\
& & 239 & & & & & \\
\end{tabular}




\section{APPENDIX II}

\section{Results of Principal Component Analyses}

Table 1. Principal Component Analysis for correlated variables demonstrating exploratory behaviour for week 1 and week 2 .

\begin{tabular}{cccc}
\hline \multicolumn{4}{c}{ Week 1 } \\
\hline \multicolumn{4}{c}{ Initial eigenvalues } \\
\hline Component & Total & \% of Variance & Cumulative \% \\
\hline 1 & 3.510 & 87.749 & 87.749 \\
2 & 0.488 & 12.201 & 99.950 \\
3 & 0.002 & 0.045 & 99.995 \\
4 & 0.000 & 0.005 & 100 \\
\hline \multicolumn{4}{c}{ Initial eigenvalues } \\
\hline Component & Total & \% of Variance & Cumulative \% \\
\hline 1 & 3.641 & 81.029 & 91.029 \\
3 & 0.354 & 0.095 & 99.891 \\
4 & 0.004 & 0.014 & 99.986 \\
\hline
\end{tabular}


Table 2. Principal Component Analysis for correlated variables demonstrating boldness for week 1 and week 2 .

\begin{tabular}{cccc}
\hline \multicolumn{4}{c}{ Week 1 } \\
\hline \multicolumn{4}{c}{ Initial eigenvalues } \\
\hline Component & Total & \% of Variance & Cumulative \% \\
\hline 1 & 3.491 & 87.281 & 87.281 \\
2 & 0.485 & 12.137 & 99.419 \\
3 & 0.019 & 0.482 & 99.901 \\
4 & 0.004 & 0.099 & 100 \\
\hline \multicolumn{5}{c}{ Initial eigenvalues } \\
\hline Component & Total & \% of Variance & Cumulative \% \\
\hline 1 & 3.238 & 80.956 & 80.956 \\
3 & 0.670 & 16.752 & 97.707 \\
4 & 0.087 & 2.184 & 99.891 \\
& 0.004 & 0.109 & 100 \\
\hline
\end{tabular}


Table 3. Principal Component Analysis for correlated variables demonstrating exploratory behaviour and boldness for week 1 for females with successful mate-choice copying trials $(n=25)$.

\begin{tabular}{cccc}
\hline \multicolumn{4}{c}{ Exploration } \\
\hline \multicolumn{4}{c}{ Initial eigenvalues } \\
\hline Component & Total & \% of Variance & Cumulative \% \\
\hline 1 & 3.238 & 80.959 & 80.959 \\
2 & 0.757 & 18.923 & 99.882 \\
3 & 0.004 & 0.107 & 99.989 \\
4 & 0.000 & 0.011 & 100 \\
\hline \multicolumn{4}{c}{ Initial eigenvalues } \\
\hline Component & Total & \% of Variance & Cumulative \% \\
\hline 1 & 3.375 & 84.377 & 84.377 \\
3 & 0.595 & 14.876 & 99.253 \\
4 & 0.025 & 0.616 & 99.868 \\
\hline
\end{tabular}


Table 4. Principal Component Analysis for correlated variables demonstrating exploratory behaviour and boldness for week 2 for females with successful mate-choice copying trials $(\mathrm{n}=12)$.

\begin{tabular}{cccc}
\hline \multicolumn{4}{c}{ Exploration } \\
\hline \multicolumn{4}{c}{ Initial eigenvalues } \\
\hline Component & Total & \% of Variance & Cumulative \% \\
\hline 1 & 3.547 & 88.663 & 88.663 \\
2 & 0.444 & 11.091 & 99.754 \\
3 & 0.009 & 0.218 & 99.972 \\
4 & 0.001 & 0.028 & 100 \\
\hline \multicolumn{4}{c}{ Initial eigenvalues } \\
\hline Component & Total & \% of Variance & Cumulative \% \\
\hline 1 & 3.681 & 92.029 & 92.029 \\
3 & 0.281 & 7.017 & 99.046 \\
4 & 0.037 & 0.918 & 99.964 \\
\hline
\end{tabular}


Table 5. Eigenvalues for behavioural measures for PC1 scores calculated for a) exploratory behaviour in a novel environment ( $\mathrm{n}=30$ for both weeks), b) boldness in the face of predation ( $\mathrm{n}=30$ for both weeks), c) exploratory behaviour in a novel environment for females with successful mate-choice copying trials $(n=25$ week 1,12 week 2), and d) boldness in the face of predation for females with successful mate-choice copying trials $\quad(\mathrm{n}=25$ week 1,12 week 2$)$.

Week 1

\section{a) Exploratory behaviour} Latency to exit refuge Total distance moved $-0.771$ $-0.846$

Time moving in open zone

0.984

0.988

Time spent in open zone

0.986

0.988

0.987

0.987

\section{b) Boldness}

Latency to exit refuge

Frequency of inspection

0.983

0.962

bouts

Total time spent inspecting

0.982

0.987

Minimum distance

0.981

0.959

approached

\section{c) Exploratory behaviour}

Latency to exit refuge

$-0.563$

$-0.798$

Total distance moved

0.987

0.987

Time moving in open zone

0.987

0.986

Time spent in open zone

0.987

0.982

\section{d) Boldness}

Latency to exit refuge

$-0.883$

Frequency of inspection

0.987

0.980

bouts

Total time spent inspecting

0.978

0.992

Minimum distance

0.974

0.978 approached

The PC1 vectors for week 1 and week 2, respectively, were highly correlated in all cases [(a) $r=0.99$, (b) $r=0.99$, (c) $r=0.98$, (d) $r=0.99]$. 